\title{
Does decentralization of decisions increase the stability of large groups?
}

\author{
Tjaša Bjedov ${ }^{\mathrm{a}}$, Simon Lapointe ${ }^{\mathrm{b} *}$, Thierry Madiès ${ }^{\mathrm{c}}$, \\ Marie Claire Villeval ${ }^{\mathrm{d}, \mathrm{e}}$
}

This version: 09 May 2018

\begin{abstract}
Using a laboratory experiment with nested local and global public goods, we analyze the stability of global groups when individuals have the option to separate, according to the degree of decentralization of decision-making. We show that increasing the number of decisions made at the local level within a smaller group reduces the likelihood that individuals vote in favor of a configuration that includes no global good for interacting only within their local group. Voting for such a configuration is more likely when global group members are less cooperative and local group members are more cooperative. Reinforcing local group identity has no impact on votes.
\end{abstract}

Keywords: Decentralization; break-up of groups; voting behavior; public goods; experiment.

JEL Classification: C91, D72, H77

${ }^{*}$ Corresponding Author.

${ }^{a}$ Swiss Distance Learning University, Ueberlandstrasse 12 CH-3900 Brig, Switzerland. Email: tjasa.maillard-bjedov@unidistance.ch.

b VATT Institute for Economic Research, Arkadiankatu 7, 00100 Helsinki, Finland. Email: simon.lapointe@vatt.fi

c University of Fribourg, Bd. de Pérolles 90, 1700 Fribourg, Switzerland. Email: thierry.madies@unifr.ch

${ }^{\mathrm{d}}$ University of Lyon, CNRS, GATE, 93 Chemin des Mouilles, F-69130, Ecully, France. Email: villeval@gate.cnrs.fr.

${ }^{\mathrm{e}}$ IZA, Bonn, Germany.

This research was supported by a grant from the University of Fribourg and was performed within the framework of the LABEX CORTEX (ANR-11-LABX-0042) of Universite de Lyon, within the program Investissements d'Avenir (ANR-11-IDEX-007) operated by the French National Research Agency (ANR). The authors wish to thank the editor and two anonymous referees for helpful comments and suggestions. The authors are also grateful to Q. Thévenet for programming the experiment, and to P. de Donder, D. Masclet, S. Paty, E. Spolaore and M. Willinger for helpful comments on a previous version. We also benefited from discussions with researchers at the IQSS (Harvard University), and from presentations at seminars at the Universities of Fribourg and Lyon, and at the following conferences: EEA 
(Lisbon), AFSE (Nice), Journées de Microéconomie Appliquée (Besançon), and PEARL (Santiago do Compostella).

\section{Introduction}

Independently of the socio-economic, cultural, or political environment, all kinds of societies were organized in groups from the earliest times. Moreover, individuals are often members of numerous, sometimes overlapping, groups. In some circumstances, however, these groups may break up into their constitutive factions. Political secessionist movements are topical examples of such situations, illustrated by the recent examples of South Sudan, Scotland, or Catalonia, (Alesina and Spolaore, 1997; 2003; Bolton and Roland, 1997; Abbink and Brandts, 2016). The risk of break-up is present in other contexts as well. An example is the demergers of municipalities in some OECD countries after waves of mergers (De Souza et al., 2015; Lapointe, 2018). Political parties are also often composed of different factions that can decide to separate because of opposing political views (Ceron, 2015). In the private sector, break-ups of strategic alliances also occur in cases of strong disagreements between the partner enterprises (Greve et al., 2010).

When a serious threat of separation is present, institutions can be modified to accommodate the grievances of the group threatening to quit. For example, political parties are often ruled in a top-down fashion but they must sometimes give in to demands of specific factions to avoid facing a break-up (Ceron, 2015). ${ }^{1}$ A similar dynamic is at play when central governments devolve some power to the local level to prevent secessions of regions.

Our main research question is whether increasing the number of decisions made in smaller, lower-level groups (which we call "decentralization") is an effective tool to quell the desire of individuals to break up the larger group. Once again, following on the

\footnotetext{
${ }^{1}$ This is well illustrated by the example of the French Socialist Party, which initially granted its different factions more autonomy, trying to prevent a split in the party.
} 
example of political secessions, some authors argue that greater regional autonomy may increase the confidence of citizens that their interests are well represented (Sorens, 2012), thus appeasing secessionist movements. However, it could also have the opposite effect (Sorens, 2004; Miodownik and Cartte, 2010; Spolaore, 2008). More generally, there is a trade-off between the higher efficiency provided theoretically by large groups, and the better matching between preferences in smaller groups. In a controlled environment, researchers have studied how groups, especially large and efficient ones, can form endogenously with the help of institutions such as punishment, reputation building, or voting (e.g., Page et al., 2005; Charness and Yang, 2014). Our paper instead focuses on cases where subjects can belong to multiple groups of different sizes and vote on their collective group membership. By manipulating the institutional rules in place, we can study experimentally how the number of decisions made in smaller groups impacts the willingness to break up large groups and the stability of the latter. ${ }^{2}$

Precisely, our design is based on a voluntary contribution mechanism game with multiple public goods. Groups of nine subjects are formed by aggregating three subgroups of three subjects each. Each subject is a member of both a global group and a local group. The nine members of a global group can contribute to global public goods, while each of the members of a sub-group can also contribute to local public goods. Although their marginal per capita return is lower than that of local public goods, global public goods have a higher potential social return because the global groups are three times bigger than the local groups.

Our experiment uses a $2 \times 2$ design. One dimension manipulates the level of decentralization of decision-making through the configuration of the public goods available. We represent decentralization as an increased number of decisions made in

\footnotetext{
${ }^{2}$ In our design, voting for the configuration with three local public goods corresponds to the dissolution of the global group. In real settings, secessions take frequently the form of a region separating from the rest of the country, but there are also examples in which the country itself dissolves (e.g., Yugoslavia, USSR).
} 
exclusive interaction with the other members of the local, smaller group, compared to the number of decisions made in the global, larger group. The other dimension varies the salience of the local group identity. In one condition local groups have a minimal group identity, as they are simply formed randomly. In another condition, we reinforce the local group identity by forming triples based on the closest proximity of the subjects' opinions on various topics elicited in a preliminary questionnaire. This variation allows us to test whether subjects that more intensely identify to the local group are more likely to vote for the configuration that includes no global good (i.e., a break-up of the global group), as the results of Ahmed (2007) and Chakravarty and Fonseca (2014) would suggest.

The experiment is composed of three parts. In part one, subjects can contribute to three local (identical) public goods. In part 2, they can contribute to both local and global public goods. We vary between-subjects the number of each type of public goods available. In the Centralization treatment subjects contribute to two global (identical) public goods and to one local public good; in the Decentralization treatment they contribute to one global public good and two local public goods. At the beginning of the third part, subjects vote over the two regimes experienced in parts one and two and play a new set of periods under the configuration that obtained the majority in at least two of the three local groups. If the majority of local groups vote for the configuration that includes no global good (thus choosing to interact only within the local group), the global group breaks up and the global public good is no longer available. ${ }^{3}$

\footnotetext{
${ }^{3}$ To control for order effects, we invert the order of Parts 1 and 2 in half of our sessions. Half of the subjects were contributing to global public goods in the periods right before the time of the vote (Part 2), while the other half contributed to global public goods in Part 1. Depending on the experimental session, the vote thus had one of two meanings: either subjects voted directly for a dissolution or "break-up" of the global group (i.e., like a secession), or they voted against the reinstatement or "re-unification" of the global group. Both interpretations, however, relate to the stability of the global group. To keep the discussion readable, the text will refer to subjects voting "for the configuration that includes no global good," including both secession from the global group, and opposition to its re-unification. In our analysis, we control for this order effect.
} 
Overall, we therefore obtain four different treatments played between-subjects and with controls for ordering effects: centralization with minimal local group identity, centralization with reinforced local identity, decentralization with minimal local identity, and decentralization with reinforced local identity. This design allows us to test the effects of decentralization and reinforced local group identity both on the contributions to local and global public goods and on the likelihood of voting for the configuration that includes no global good.

Our results show that giving more decisions to the local groups (which we define as decentralization) increases contributions to local public goods without altering cooperation at the global level. Moreover, decentralization decreases the likelihood that subjects vote for the configuration without a global good, even after controlling for contributions to local and global goods, or for the earnings of the individual from each type of public good. In addition, subjects vote less often for the configuration without a global good when their global group is more cooperative and their local group less cooperative. In contrast, reinforcing local group identity does not affect contributions, voting behavior, or the impact of decentralization on the likelihood of voting for the configuration without a global good. These results are important because they show that even in a very stylized and anonymous environment where all local (or global) public goods are identical and fungible, simply increasing the relative number of decisions made within a smaller group is sufficient to reduce the temptation to break up with larger groups, that are theoretically able to reach a higher level of efficiency when people cooperate.

The remainder of the paper is organized as follows. Section 2 surveys the related literature. Section 3 describes the experimental design and procedures and presents our predictions. Section 4 reports the results and Section 5 discusses them and concludes. 


\section{Related Literature}

Our paper is related to various strands in the literature. First, previous experiments have introduced multiple public goods and multiple groups. In particular, Bernasconi et al. (2009) explore how contributions differ when a group of subjects can contribute to one or to multiple public goods. The total contribution of individuals is higher when a single public good is later split into two identical public goods. In McCarter et al. (2014), subjects also face multiple public goods, but in one treatment they play two public good games with the same group of players, whereas in the other treatment, each game is played with a different group. In the latter, subjects shift their contributions towards the more cooperative group (see also Falk et al., 2013). In our design, we also introduce multiple public goods but some are local and others are global, and the members of the local groups can interact with other groups for the provision of global public goods.

Our experiment also contributes to the experimental literature manipulating the group size and the marginal per capita return (the factor that multiplies the total amount of contributions invested in the public good). Regarding group size, Isaac and Walker (1988) and Isaac et al. (1994) have shown that for a given MPCR a higher group size increases average contributions. Yet, as we have two groups of different sizes with contribution decisions taken at the same time, we do not expect to observe a similar contribution profile to the one reported by Isaac and Walker (1988) and Isaac et al. (1994). The papers by Fellner and Lünser (2014), Blackwell and McKee (2003) and McCarter et al. (2013) are closer to our experimental design as they also have simultaneous groups of different sizes. The literature has also shown that a higher MPCR increases contributions (Marwell and Ames, 1979; Isaac et al., 1984; 1985; see survey by Ledyard, 1995). Experiments including both local and global public goods combine both dimensions. In Wachsman (2002) the subjects' endowment can be allocated to a local group account and to a global group account with a lower MPCR. 
When no communication is allowed with local group members, subjects allocate more resources to the global account, suggesting that they attach greater importance to the potential payoff of the global account than to the higher MPCR of the local account. Blackwell and McKee (2003) keep the local MPCR fixed and vary the global MPCR. When the average per capita return of the global public good exceeds that of the local good, individuals contribute more to the global public good but do not reduce their contributions to the local good. However, Blackwell and McKee (2011) find that individuals contribute more to a local public good. In Fellner and Lünser (2014) also, stable cooperation is achieved only for local public goods. Subjects first attempt to cooperate to the global public good but cooperation rapidly decays while it remains stable for the local good. Moreover, when endowments are heterogeneous across local groups, subjects contribute more to the local public good and less to the global one (Nitta, 2014). In contrast, we hold the endowment equal and constant, we introduce multiple public goods at the local or at the global level, and we allow subjects to vote to sever links with the other local groups.

Our experiment is thus also related to public goods games endogeneizing group formation (e.g., Ehrhart and Keser, 1999; Cinyabuguma et al., 2006). In particular, Page et al. (2005) show that voluntary association can mitigate the free-rider problem. By combining mobility and voting on the exclusion of individual members, Charness and Yang (2014) observe that the grand coalition can form with a high level of cooperation. In contrast, we start from a situation in which the global group coexists with local groups. Other differences are that the decision on the composition of public goods holds for the whole group, not for individuals, and subjects cannot choose their local group members. Subjects can vote on whether or not they want the presence of a global good, 
and that decision is made at the group level. We can thus study whether the threat of dissolving the global group discourages free riding in global groups. ${ }^{4}$

Finally, this paper is related to studies on how group identity affects cooperation. In particular, Hoffman et al. (1996), Akerlof and Kranton (2000), and Buchan et al. (2006) have shown that group identity and social distance, defined as the perceived affinity and nearness between people, are important factors in economic decision-making. Individuals treat the members of their group differently than members of other groups (Festinger 1954; Tajfel et al. 1971; Tajfel and Turner 1979). Group identity reinforces social preferences vis-à-vis in-groups (Chen and Li, 2009); it strengthens cohesion (e.g., Rege and Telle, 2004) and cooperation (e.g., Kramer and Brewer, 1984; Chakravarty and Fonseca, 2014). Simultaneously, it may reduce trust in out-groups. For example, Luttmer (2001) shows that individuals dislike providing social welfare when recipients are from another ethnic group. Carpenter and Cardenas (2011) identify an amplified impact of local cultures when groups are mixed. And de Olivera et al. (2015) find a negative impact of ethnic heterogeneity on the provision of local public goods. Our paper extends this literature by studying how reinforced $v s$. minimal local group identity affects cooperation within a local group and within a global group where interactions also involve other local groups, and how it influences voting behavior.

\section{Experimental design, conjectures and procedures}

We first introduce our experimental design and then, we present our behavioral conjectures. Finally, we describe the procedures.

\footnotetext{
${ }^{4} \mathrm{~A}$ recent literature has identified a democracy premium in public good games when an institutional arrangement is the result of a vote compared to when it is imposed exogenously (e.g., Tyran and Feld, 2006; Dal Bó et al., 2010; Sutter et al. 2010; Markussen et al., 2014). We can observe behavior when the only local public goods are imposed exogenously and when they result from a secession vote. However, these two situations do not occur in the same part of the experiment. Because of the decay of cooperation over time, we cannot identify cleanly the existence of a democracy premium.
} 


\subsection{Experimental design}

Our experiment is based on a $2 \times 2$ factorial design. One dimension varies the degree of decentralization of decision-making, defined as the relative number of decisions made at the local group level, and the second dimension manipulates the local group identity. We start by describing our baseline, the centralization decision-making environment with a minimal local group identity.

\subsubsection{Centralization with minimal group identity treatment}

In the Centralization with minimal group identity treatment (C-MinI, hereafter), the program forms randomly groups of nine subjects at the beginning of the session. Each group of nine subjects consists of three sub-groups of three subjects, labeled A, B and C. A group of nine subjects is called a "global group" and a sub-group of three subjects a "local group". Thus, each subject belongs both to a local group with two other subjects and to a global group that includes his local group members and the six members of the two other local groups. It is common knowledge that the composition of local and global groups is kept fixed throughout the session.

A session consists of 36 periods divided in three parts of 12 periods each. In the first part, no global public good is available and the subjects only interact with their two other local group members. At the beginning of each period, they receive an endowment of 60 ECU (Experimental Currency Units) each. They have to allocate their endowment between a private account and three local public goods that are identical, fungible and substitutable. ${ }^{5}$ They make three decisions: they choose how many ECU (between 0 and 60, included) to contribute to each local public good. The marginal per capita return (MPCR, hereafter) is 0.5 for each local public good. Thus, each unit contributed pays

\footnotetext{
${ }^{5}$ Although it seems largely artificial, we introduced a multiplicity of identical public goods because we want subjects to make the same total number of contribution decisions when we introduce both local and global public goods than when only local public goods are available. Moreover, previous studies (Bernasconi et al., 2009) have shown the positive "unpacking effect" on contributions of having two identical public goods instead of a single one.
} 
back 0.5 unit to each of the three local group members, regardless of his contribution, while the private account yields a one-to-one return. The individual payoff function is:

$$
\pi_{\text {AllLocal }, i}=\left(60-c_{i}\right)+0.5 \sum_{j=1}^{3} c_{1 j}+0.5 \sum_{j=1}^{3} c_{2 j}+0.5 \sum_{j=1}^{3} c_{3 j}
$$

where $\mathrm{c}_{i}$ is player $i$ 's total contribution to the three local public goods; $\mathrm{c}_{j}$ is each local group member's contribution to the local public good, with $j=1,2,3$.

Each of the 12 periods of the second part follows the same rules. The differences are that subjects can now contribute to one local public goods and two global public goods. They choose how many ECU (between 0 and 60, included) to contribute to the unique local public good and how many to contribute to each of the two global public goods, with the remainder kept in their private account.

The two global public goods are identical. In contrast, two differences distinguish local from global public goods. First, the MPCR is 0.2 for each global public good while it is 0.5 for the local public good. Thus, each unit contributed to a global public good pays back 0.2 to each of the nine global group members. Second, the potential contributors to the local and to the global public goods differ. While only three subjects can contribute to a local public good, all nine subjects can contribute to the global public good. Consequently, the latter has a higher social return $(0.2 * 9$ vs. $0.5 * 3)$.

In this part, the payoff of subject $i$ in a single period, $\pi_{C e n t, i}$, equals:

$$
\pi_{\text {Cent }, i}=\left(60-c_{i}\right)+0.5 \sum_{j=1}^{3} c_{j}+0.2 \sum_{k=1}^{9} c_{1 k}+0.2 \sum_{k=1}^{9} c_{2 k}
$$

where $c_{i}$ and $c_{j}$ are defined as before, and where $c_{k}$ represents each global group member's contribution to the global public goods, with $k=1, \ldots, 9 .=1, \ldots, 9$.

At the end of each period in these two parts, each subject is informed of his payoff and of the total contributions of his local group to each local good; in addition in part 2 he is also informed of the total contribution of the global group to each of the two global 
goods. Subjects receive no information on the contributions to local goods of the two local groups of which they are not member.

At the beginning of the third part, subjects have to vote on the structure of the public goods that will be implemented for the last block of 12 periods. They can vote between two options: three local public goods (as in part 1) or one local public good and two global public goods (as in part 2). ${ }^{6}$ The final outcome of the vote is based on a double majority rule. The program first calculates how many members voted in favor of three local public goods in each local group. The majority is attained when at least two members out of three voted for that configuration. Then, the program computes how many local groups voted in majority for that configuration. Again, a majority is reached when at least two local groups out of three voted for the same configuration. The third part of the experiment implements the configuration that obtained the majority vote of the three local groups, with the corresponding payoff function (equation (1) in case of break-up of the global group or (2) otherwise). The double majority rule prevents a single local group to break up with the global group, ${ }^{7}$ and thus having global groups of six members only; indeed, this would not allow us to make any comparison with the exogenous initial global groups of nine members.

The decay of cooperation over time usually observed in public good games may affect people's judgment, in the sense that they may believe that the lower levels of cooperation observed in the second part are due to a lower efficiency of the second regime compared to the first one. To account for such potential ordering effect on

\footnotetext{
${ }^{6}$ Our design exposed the subjects to each configuration before letting them vote for one of the two settings. One reason was to let subjects become familiar with each environment before voting and to give the same chance, ex ante, to each regime to be voted for. Another reason was to avoid introducing two changes at the same time if people voted for a regime that they never experienced before. This usually differs in real settings where citizens may vote for a regime they were never exposed to before. There are, however, examples of federations of countries (e.g., Ex-Yugoslavia, former USSR) that were initially independent and then experienced a period of unification to finally secede and become again independent. ${ }^{7}$ Similarly, when the game is played in the reverse order, the rule prevents a single group to impose reunification although this situation would be less constraining since local groups who are willing to contribute only to the local public goods would not be forced to contribute to the global public goods.
} 
voting, we balanced the order of the first two parts across sessions. Figure 1A in Appendix 1 displays the structure of the two versions of the C-MinI treatment.

Finally, at the end of the third part, we administered a socio-demographic questionnaire including questions on gender, age, and relative wealth of the family compared to other students (on a scale from 0 for the poorer to 10 for the wealthier).

\subsubsection{Decentralization with minimal group identity treatment}

Recall that we define "decentralization" as a larger number of decisions made among local group members rather than at the global group level. The only difference between the Decentralization - minimal group identity treatment (D-MinI, hereafter) and the CMinI treatment lies in the number of local public goods in the part where the configuration of public goods is mixed. In the D-MinI treatment, there is one global public good and two local public goods (instead of two global public goods and one local public good in C-MinI). Thus, subjects have to choose how many ECU of their endowment (between 0 and 60) to contribute to the two local group accounts and to the unique global group account. In the other of the first two parts, there are three local public goods as in the C-MinI treatment. We also balanced the order between the first two parts across sessions. Figure 1B in Appendix 1 displays the two versions of the DMinI treatment. In periods where no global public good is available the individual's payoff function, $\pi_{\text {AllLocal, } i}$, is the same as in equation (1). When the configuration is mixed, the payoff of subject $i \pi_{\text {Decent }, i}$, in a given period is:

$$
\pi_{\text {Decent }, i}=\left(60-c_{i}\right)+0.5 \sum_{j=1}^{3} c_{1 j}+0.5 \sum_{j=1}^{3} c_{2 j}+0.2 \sum_{k=1}^{9} c_{k}
$$

The objective of the D-MinI treatment is to test whether the likelihood of voting for a configuration with only local public goods is less likely when subjects had to make more decisions at the local level than at the global level in the previous parts. Indeed, a specificity of our design is that while it features entirely identical, fungible and 
substitutable public goods, it varies only the number of decision rights at the global and at the local levels across treatments. This minimal and largely artificial manipulation allows us to estimate whether the variation in the number of decisions made locally and globally affects the vote outcome.

\subsubsection{Reinforcement of local group identity}

The Centralization - reinforced Identity treatment (C-I, hereafter) and the Decentralization - reinforced Identity treatment (D-I, hereafter) are similar to C-MinI and D-MinI, respectively, except that we made the local group identity more salient. The objective is to test whether voting for a break-up of the global group is more likely when subjects share the same reinforced identity with their local group members.

To reinforce local group identity, the computer program forms local groups based on the proximity of individual opinions regarding topics unrelated to the experiment (arts, sports, surrogate mothers and genetically modified food; see Appendix 4) instead of using a purely random matching. Precisely, at the beginning of the experiment we introduce a questionnaire that contains four statements. For each statement, subjects have to report their opinion by choosing one of four possible responses: 1) I strongly disagree, 2) I disagree, 3) I agree, and 4) I strongly agree. An algorithm is used to form the local groups according to the proximity of the answers given to the four statements. It is made common knowledge that at the local level each subject is paired with the two other subjects who, in the global group of nine subjects, expressed the closest opinions to his. The members of the other two local groups have more distant opinions.

\subsection{Conjectures}

In all treatments, assuming that subjects are willing to maximize their earnings selfishly and that this is common knowledge, the sub-game perfect equilibrium of the game is to not contribute to the public goods, regardless of whether they are local or global. 
Indeed, the marginal per capita returns of both types of public goods are lower than the marginal return of the private goods. On the opposite, the socially optimal behavior is for subjects to contribute their whole endowment to a public good, since $0.5 * 3>1$ and $0.2 * 9>1$. Since the global public good is more socially efficient $(0.2 * 9>0.5 *$ 3), subjects should contribute only to the provision of the global goods. As a result, in equilibrium subjects should be indifferent regarding the break-up of the global group and at the optimum they should vote against it.

Based on previous research (e.g., surveys by Ledyard, 1995; Chaudhuri, 2011), however, we anticipate that subjects will contribute a positive amount to the public goods, they will contribute less than the social optimum and decreasingly over time. Our first conjecture pertains to how individuals allocate their contributions across local and global goods. Fellner and Lünser (2014) found that subjects initially contribute to both types of goods, but they contribute relatively more to the local good as time goes by because cooperation is easier to sustain in smaller groups. Similarly, we conjecture that subjects will contribute more on average to local than to global public goods.

Conjecture 1: Individuals contribute relatively more to local than to global public goods.

The next two conjectures concern the effect of the treatments on contributions. First, when both global and local goods are available, we conjecture that contributions to the local goods compared to the global goods will be higher in the Decentralization treatments (D-MinI and D-I) than in the Centralization ones (C-MinI and C-I, respectively). Indeed, we extrapolate from Bernasconi et al. (2009) who have shown that subjects contribute more when there are two identical public goods than a single one. Therefore, we expect that contributions will be higher to any given type of public good when subjects face multiple goods of that type.

Conjecture 2.A: Decentralization increases contributions to the local public goods compared to contributions to the global public goods. 
We conjecture that a more salient local group identity encourages contributions to local goods. Indeed, as subjects identify with the other members of their local group more strongly, we expect that they will contribute more and that cooperation will be easier to sustain at the local level, compared to when local identity is minimal. This conjecture is based on previous literature showing that individuals are more cooperative with their in-groups than with out-groups (Tajfel et al., 1971; Yamagishi et al., 1999; Chen and $\mathrm{Li}, 2009$ ) and that a more salient social group identity facilitates cooperation (Kramer and Brewer, 1984; Wit and Wilke, 1992).

Conjecture 2.B: Reinforcing local identity increases contributions to the local public goods.

We are ultimately interested in the effect of the treatments on the probability of subjects voting for continuing the experiment without the global group in the third part of the experiment.

The impact of decentralization on voting may operate through contributions: if under decentralization contributions to the local public goods are relatively higher, subjects might be more likely to vote for the configuration that includes no global good because they anticipate they could earn less in this environment. Indeed, this configuration may help the members of a local group to coordinate by concentrating all their contributions to the local goods without having to suffer from free-riding by other local groups in the provision of global public goods. A second effect could, however, operate in the opposite direction, for a given level of contributions. Indeed, the desire of a local group to be in the configuration without a global good might be reduced by a relatively higher number of decisions made at the local level (capturing a lower distance between decision-making and the subjects or in the real world, a better match between preferences and provided public goods). Our local public goods are perfectly 
substitutable, but we still conjecture that for given contributions, decentralization reduces the likelihood of voting for the configuration that includes no global good.

Conjecture 3.A: Controlling for the contributions to the global public goods and for the contributions to the local public goods, decentralization decreases the probability of voting for the configuration that includes no global good.

Reinforcing local identity may encourage individuals to vote for the configuration without a global good. This is not only because local groups may be relatively more cooperative in this environment, but also because subjects may feel closer to in-groups than to out-groups and they may have a preference for group-togetherness. ${ }^{8}$

Conjecture 3.B: Controlling for the contributions to the global public goods and for the contributions to the local public goods, reinforced local identity increases the probability of voting for the configuration that includes no global good.

We also test whether decentralization and reinforced local identities have antisynergistic effects on voting. For given mean contributions, the desire of a local group to vote for the configuration that includes no global good might be influenced both by the relative number of decisions made at the local level and by the closeness with ingroups.

Conjecture 3.C: Controlling for the contributions to the global public goods and for the contributions to the local public goods, reinforcing local identity decreases the effect of decentralization on the probability of voting for the configuration that includes no global good.

Finally, we conjecture that the others' mean contributions affect the individuals' votes. A higher mean contribution of local group members is expected to increase the likelihood of voting for the configuration without a global good. Indeed, the literature has shown that when players can change group or create groups, they rarely form the grand coalition although it would be optimal (Ehrhart and Keser, 1999), except when mobility is combined with the right to exclude group members (Cinyabuguma et al.,

\footnotetext{
${ }^{8}$ This could be compared to tastes for own-ethnic group neighborhoods (e.g., Wong, 2013). In contrast, reinforcing global group identity could have had the opposite effect. For example, Rand et al. (2009) showed that before primary elections in the Democratic Party in the U.S., the supporters of each candidate had a strong bias against the supporters of the other camp; this local group bias disappeared once the primary elections determined which candidate would run for the general elections.
} 
2006; Charness and Yang, 2014). In our design, if local group members are cooperators, voting for the dissolution of the global group is a way to concentrate contributions in the sole local public goods and protect against free riding by non-locals in the global group. Conversely, since global goods have potentially greater payoffs given their larger number of members, subjects who are matched with more cooperative global group members should be less likely to vote for its break-up.

Conjecture 4: Higher mean contributions by other group members to the local public goods (respectively, to the global public goods) increase (respectively, decrease) the probability of voting for the configuration that includes no global good.

\section{$\underline{\text { 3.3. Procedures }}$}

The experiment consists of 33 sessions conducted at GATE-Lab, Lyon, France. The 432 participants (108 for each of the four treatments) were recruited from local engineering and business schools, using the ORSEE software (Greiner, 2015). $55.79 \%$ of the participants are females and the mean age is 22.97 years $($ S.D. $=6.22)$. Six sessions were conducted for each treatment (three sessions in each order between parts 1 and 2). The experiment was computerized using ZTree (Fischbacher, 2007). Table A1 in Appendix 2 summarizes the characteristics of these sessions.

Upon arrival, subjects were randomly assigned to a computer after drawing a tag from an opaque bag. Instructions (see Appendix 3) were distributed at the beginning of each part and read aloud. On average, a session lasted 90 minutes, including payment. Subjects were paid the sum of their earnings in each period, at the rate of $100 \mathrm{ECU}=$ 0.45 Euro. In addition, they were paid a $€ 5$ show-up fee. On average, they earned $€ 17.12$ (S.D.=1.68). Payments were made in cash and privately in a separate room.

\section{Results}

In this section, we first analyze contribution behavior before reporting on voting. 


\subsection{Decentralization, local identity and contribution behavior}

The first result supports our first conjecture:

Result 1: Subjects contribute relatively more to local public goods over time than to global public goods.

Support for Result 1. Table 1 displays the average individual contributions to local and to global public goods by treatment, order, and part. For part 3, it distinguishes the cases in which break-up of the global group occurred or did not occur. In the lower panel, the table reports the mean percentages of maximum efficiency attained in the various configurations. Table 1 also reports the $p$-values of Mann-Whitney tests (MW, hereafter) in which we compare each treatment to C-MinI. ${ }^{9}$ As a complement, Figure 1 displays the evolution of the average individual contributions over the 36 periods, pooling all treatments together but separating the two possible orderings of sessions and the cases with and without a dissolution of the global group in part 3.

\footnotetext{
${ }^{9}$ Unless specified otherwise, all non-parametric tests are two-tailed throughout the paper, and an independent observation corresponds to the contributions of each global group averaged over each part of 12 periods.
} 
Table 1: Summary statistics on contributions, by part, order and treatment

\begin{tabular}{|c|c|c|c|c|c|c|}
\hline & Part & $\begin{array}{l}\text { Order: } \\
\text { first part }\end{array}$ & C-MinI & D-MinI & C-I & D-I \\
\hline \multirow{6}{*}{$\begin{array}{l}\text { Contributions } \\
\text { to local public } \\
\text { goods }\end{array}$} & 1 & Mixed & $15.46(4.62)$ & $\begin{array}{l}28.80(7.48)^{* * *} \\
p=0.006\end{array}$ & $\begin{array}{l}20.04(3.52) \\
p=0.109\end{array}$ & $\begin{array}{l}31.75(5.04)^{* * *} \\
p=0.004\end{array}$ \\
\hline & 2 & Mixed & $28.83(7.42)$ & $\begin{array}{l}27.61(6.88) \\
p=0.631\end{array}$ & $\begin{array}{l}32.10(5.70) \\
p=0.470\end{array}$ & $\begin{array}{l}34.07(3.76) \\
p=0.262\end{array}$ \\
\hline & 1 & $3 \mathrm{~L}$ & $30.12(7.89)$ & $\begin{array}{l}28.58(10.50) \\
p=0.873\end{array}$ & $\begin{array}{l}32.41(5.38) \\
p=0.873\end{array}$ & $\begin{array}{l}30.28(2.12) \\
p=0.749\end{array}$ \\
\hline & 2 & $3 \mathrm{~L}$ & $11.03(4.57)$ & $\begin{array}{l}10.36(6.55) \\
p=0.688\end{array}$ & $\begin{array}{l}9.60(2.61) \\
p=0.522\end{array}$ & $\begin{array}{l}14.33(3.92) \\
p=0.262\end{array}$ \\
\hline & $\begin{array}{l}3 \text { with } \\
\text { break-up }\end{array}$ & - & $17.36(8.81)$ & $\begin{array}{l}9.49(2.82) \\
p=0.142\end{array}$ & $\begin{array}{l}21.28(6.09) \\
p=0.624\end{array}$ & $\begin{array}{l}24.07(8.10) \\
p=0.180\end{array}$ \\
\hline & $\begin{array}{l}3 \text { no break- } \\
\text { up }\end{array}$ & - & $9.93(3.45)$ & $\begin{array}{l}13.69(5.90) \\
p=0.165\end{array}$ & $\begin{array}{l}13.06(6.53) \\
p=0.418\end{array}$ & $\begin{array}{l}17.14(5.92)^{* *} \\
p=0.017\end{array}$ \\
\hline \multirow{5}{*}{$\begin{array}{l}\text { Contributions } \\
\text { to global } \\
\text { public } \\
\text { goods }\end{array}$} & 1 & Mixed & $15.92(3.43)$ & $\begin{array}{l}10.06(4.69)^{*} \\
p=0.055\end{array}$ & $\begin{array}{l}15.04(4.79) \\
p=0.631\end{array}$ & $\begin{array}{l}10.53(4.34) \\
p=0.832\end{array}$ \\
\hline & 2 & Mixed & - & - & - & - \\
\hline & 1 & $3 \mathrm{~L}$ & - & - & - & - \\
\hline & 2 & $3 \mathrm{~L}$ & $8.38(5.28)$ & $\begin{array}{l}7.97(5.85) \\
p=0.631\end{array}$ & $\begin{array}{l}13.63(4.84)^{*} \\
p=0.078\end{array}$ & $\begin{array}{l}7.95(1.89) \\
p=0.749\end{array}$ \\
\hline & $\begin{array}{l}3 \text { no break- } \\
\text { up }\end{array}$ & - & $6.62(3.81)$ & $\begin{array}{l}7.01(4.42) \\
p=0.817\end{array}$ & $\begin{array}{l}9.12(4.39) \\
p=0.354\end{array}$ & $\begin{array}{l}6.34(4.15) \\
p=0.832\end{array}$ \\
\hline \multirow{6}{*}{$\begin{array}{l}\text { Average } \\
\text { percentage of } \\
\text { maximum } \\
\text { efficiency } \\
\text { reached } \\
(\%)\end{array}$} & 1 & Mixed & 74.51 & $\begin{array}{l}76.34 \\
p=0.631\end{array}$ & $\begin{array}{l}75.98 \\
p=0.470\end{array}$ & $\begin{array}{l}78.05 * * * \\
p=0.004\end{array}$ \\
\hline & 2 & Mixed & 82.67 & $\begin{array}{l}82.00 \\
p=0.631\end{array}$ & $\begin{array}{l}84.50 \\
p=0.470\end{array}$ & $\begin{array}{l}85.58 \\
p=0.262\end{array}$ \\
\hline & 1 & $3 \mathrm{~L}$ & 83.40 & $\begin{array}{l}82.54 \\
p=0.873\end{array}$ & $\begin{array}{l}84.66 \\
p=0.200\end{array}$ & $\begin{array}{l}82.37 \\
p=0.749\end{array}$ \\
\hline & 2 & $3 \mathrm{~L}$ & 66.87 & $\begin{array}{l}66.25 \\
p=0.873\end{array}$ & $\begin{array}{l}69.93 \\
p=0.200\end{array}$ & $\begin{array}{l}68.08 \\
p=0.262\end{array}$ \\
\hline & $\begin{array}{l}3 \text { with } \\
\text { break-up }\end{array}$ & - & 76.51 & $\begin{array}{l}71.93 \\
p=0.142\end{array}$ & $\begin{array}{l}78.48 \\
p=0.624\end{array}$ & $\begin{array}{l}80.03 \\
p=0.180\end{array}$ \\
\hline & $\begin{array}{l}3 \text { no break- } \\
\text { up }\end{array}$ & - & 65.05 & $\begin{array}{l}67.08 \\
p=0.354\end{array}$ & $\begin{array}{l}68.36 \\
p=0.247\end{array}$ & $\begin{array}{l}68.18 * * \\
p=0.017\end{array}$ \\
\hline
\end{tabular}

Notes: Numbers indicate mean values. Standard deviations are in parentheses. "3L" means that in the first part there were 3 local public goods and no global goods; "mixed" means that according to the treatment, in the first part there were 2 global and 1 local public goods, or 1 global and 2 local public goods. ***, **, and $*$ indicate $p<0.01, p<0.05, p<0.10$ in two-tailed Mann-Whitney tests, in which each treatment is compared to C-MinI.

Table 1 and Figure 1 indicate that when the experiment starts with both types of public goods, subjects initially contribute more to local than to global public goods, and cooperation is sustained longer for those goods, while it declines rapidly for global goods. For this order, pooling all treatments, the mean contribution in part 1 is 24.02 for local public goods and 12.89 for global goods (Wilcoxon test, W hereafter, $p=0.000$ ). There is a large restart effect in Period 13, when subjects are faced only with local public goods. When the experiment starts with only local public goods, subjects initially contribute large amounts in the first part. Then in part 2, while contributions to the 
global goods initially surpass those to the local goods, the pattern is reversed after three periods. Cooperation is again sustained longer for local public goods. For this order, pooling all treatments, the mean contribution in part 2 is 11.11 for local public goods and 8.60 for global goods (MW, $p=0.045$ ).

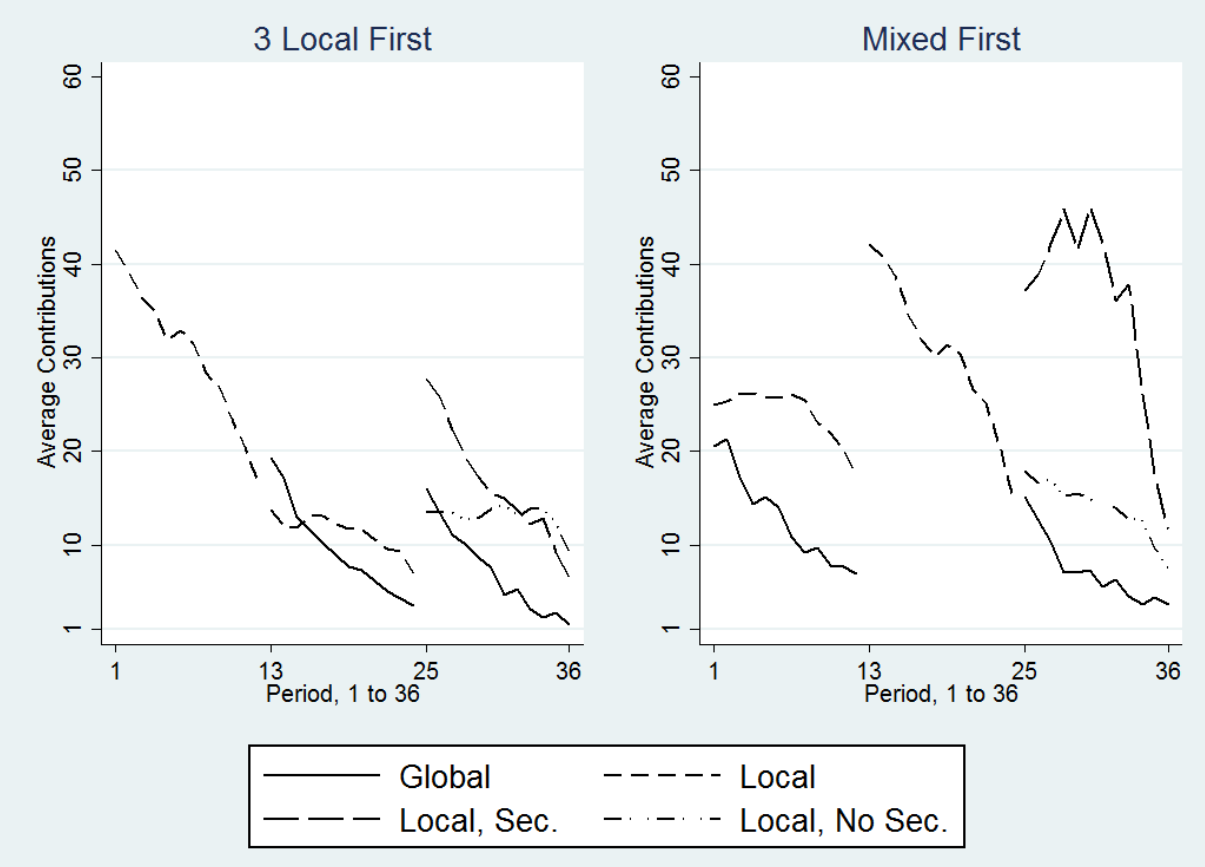

Figure 1: Evolution of the average individual contributions across all treatments, by type of public goods and ordering

Figure 1 also illustrates that in groups that obtained the dissolution of the global group, after an initial boost (especially in mixed first) the mean cooperation decreases until the end of the game. Wilcoxon tests at the global group level show that in all treatments the mean total individual contributions (to both local and public goods) in the first two parts before the vote is significantly different (higher) than in the last part (Local goods: C-MinI: $p=0.004$, D-MinI: $p=0.003$, C-I: $p=0.008$, D-I: $p=0.006$. Global goods: C-MinI: $p=0.018$, D-MinI: $p=0.011, \mathrm{C}-\mathrm{I}: p=0.011, \mathrm{D}-\mathrm{I}: p=0.008)$.

Our two next results concern the effects of the treatments. Result $2 \mathrm{~A}$ supports conjecture 2.A.

Result 2.A: Decentralization increases contributions to local public goods; it has almost no effect on contributions to global public goods. 
Support for Result 2.A. Table 1 shows that compared to C-MinI, contributions to local public goods in part 1 are significantly higher in D-MinI $(p=0.006)$ and in D-I $(p=0.004)$, when there is a mix of local and global public goods available. This difference disappears in part 2 , or when only three local public goods are available. After the vote in part 3, contributions to local public goods are higher but this is significant only in the D-I treatment when no global group break-up occurred $(p=0.017)$. Contributing more to the local public goods when the structure is more decentralized reduces contributions to global public goods in all parts, but this is significant only in part 1 when local identity is not reinforced $(p=0.055$ in D-MinI compared to C-MinI).

Incidentally, the lower panel of Table 1 indicates that the average percentage of the maximum efficiency reached exceeds 80 in all treatments when only local public goods are available, while it is lower than 80 when there is a mix of global and local public goods. This percentage is significantly higher in the D-I treatment than in C-MinI, at least for the first and last 12 periods when no break-up of the global group occurred.

To further analyze the determinants of contributions when both types of public goods are available, Table 2 presents the estimates from random-effects OLS models with standard errors clustered at the global group level. The data only includes contributions in periods 1 to 24 , when the structure of public goods is exogenous. The dependent variable is the individual contribution to the local public goods in column (1), the contribution to the global public goods in column (2), and the difference between contributions to the local and to the global public goods (which captures the individual's preference for local public goods) in column (3).

The independent variables include dummy variables for the decentralization and the reinforced identity manipulations and an interaction term between these two 
dimensions. We add a dummy variable to control for the impact of starting the game with three local public goods. The independent variables include the contributions of the two other local group members to the local goods and the contributions of the eight other members to the global goods in the previous period. We add a time trend and various individual characteristics (age, gender and relative subjective wealth).

Table 2: Determinants of individual contributions to local and global public goods, and of the difference between contributions to each type, in periods with a mixed configuration

\begin{tabular}{lccc}
\hline Dependent variables & $\begin{array}{c}\text { Contributions to } \\
\text { local public goods } \\
(1)\end{array}$ & $\begin{array}{c}\text { Contributions to } \\
\text { global public goods } \\
(2)\end{array}$ & $\begin{array}{c}\text { Difference between } \\
\text { local and global } \\
(3)\end{array}$ \\
\hline Decentralization & $3.219^{* *}(1.64)$ & $-1.900(1.52)$ & $4.980^{* *}(2.04)$ \\
Reinforced local identity & $0.394(1.47)$ & $1.465(1.44)$ & $-1.056(1.69)$ \\
Decentralization * reinforced & $1.979(2.18)$ & $-0.913(1.98)$ & $2.834(2.54)$ \\
local identity & & & \\
Start with 3 local goods & $-7.144^{* * *}(1.30)$ & $-2.790^{* * *}(1.03)$ & $-4.239^{* * *}(1.46)$ \\
Mean contribution by 2 others & $0.215^{* * *}(0.02)$ & $-0.021 *(0.01)$ & $0.243^{* * *}(0.02)$ \\
to local goods in $t-1$ & & & \\
Mean contribution by 8 others & $0.002(0.01)$ & $0.033^{* * *}(0.01)$ & $-0.033^{* * *}(0.01)$ \\
to global goods in $t-1$ & & & \\
Period in the part (1 to 12) & $-0.414 * * *(0.11)$ & $-0.909^{* * *}(0.10)$ & $0.479^{* * *}(0.16)$ \\
Age & $0.030(0.10)$ & $0.245^{* * *}(0.07)$ & $-0.216^{*}(0.12)$ \\
Female & $1.487(1.06)$ & $1.762^{* * *}(0.87)$ & $-0.271(1.22)$ \\
Relative wealth (1 to 10) & $-0.420^{*}(0.27)$ & $-0.382^{*}(0.22)$ & $-0.033(0.29)$ \\
Constant & $14.315^{* * *(3.21)}$ & $11.623^{* * *}(2.68)$ & $2.765(4.01)$ \\
\hline Number of observations & 4752 & 4752 & 4752 \\
$\mathrm{R}^{2}$ & 0.339 & 0.149 & 0.208 \\
$\chi^{2}$ & $570.40^{* * *}$ & $357.74 * * *$ & $301.35^{* * *}$ \\
\hline
\end{tabular}

Notes: Standard errors, clustered at the global group level, are in parentheses. $* * *, * *$ and $*$ indicate significance at the $0.01,0.05$ and 0.1 level, respectively. Estimations only include periods in which subjects had to contribute to both types of goods.

Supporting Result 2A, column (1) indicates that decentralization (i.e., two local and one global decisions) increases individual contributions to local goods significantly. In contrast, column (2) shows that decentralization has no significant effect on contributions to global public goods. Put differently, when faced with two local decisions, subjects increase their contributions to local goods although they are substitutable, but the opposite is not true: when faced with two global decisions, subjects do not increase their contributions to global goods. Column (3) indicates that 
decentralization increases significantly the gap in contributions between the local and the global public goods.

The next result rejects conjecture $2 \mathrm{~B}$ :

Result 2.B. Reinforcing local group identity does not affect individual contributions.

Support for Result 2.B. Table 2 indicates that the contributions of fellow group members affect significantly individuals' contribution, which is consistent with conditional cooperation, but the effect is not symmetric for local and for global public goods. As members of an individual's local group contribute more to the local good, that subject then contributes more to the local public goods and less to the global public goods, which increases the gap between contributions to local and to global goods. Conversely, as members of an individual's global group contribute more to the global public goods, he contributes relatively more to the global public good but does not modify his contributions to local public goods, which decreases the gap between contributions to the different types of goods.

Table 1 has shown that contributions to the global public goods in the second part are higher in C-I compared to the C-MinI treatment (MW, $p=0.078$ ). However, in the three columns of Table 2, the reinforced local group identity variable and its interaction with decentralization never reach conventional levels of significance.

Finally, Table 2 shows that both types of individual contributions decline over time. Supporting also Result 1, we find that as time passes, a larger share of total contributions goes to local public goods (see column (3)). Contributions are also on average lower when the subjects experience three local goods in the beginning of the session, but that result is due to the fact that we only use the data from periods in which both local and global public goods are present. These periods come later for the subjects who started the session with the three local goods. 


\subsection{Decentralization, local identity and votes}

We turn now to the analysis of the subjects' votes. 159 subjects (36.81 per cent of all subjects) voted for the configuration that includes no global good. Due to the double majority procedure, this resulted in 16 global groups (33.33 per cent of all global groups) experiencing part three without global goods. Our next result supports conjecture $3 \mathrm{~A}$.

Result 3.A: Controlling for the contribution levels, having made more decisions at the local level in the past decreases the likelihood of voting for the configuration that includes no global good.

Support for Result 3.A. The percentages of individual votes for the configuration without a global good are 36.11 in D-MinI, 31.48 in D-I, and 38.89 in C-I. Proportion tests indicate that these values are not significantly different from the 40.74 per cent found in the C-MinI treatment ( $p=0.484, p=0.157$, and $p=0.781$, respectively). Pooling the two identity conditions together, we find that 39.81 per cent vote for the configuration without a global good under centralization and 33.79 per cent under decentralization $(p=0.195)$. Similarly, pooling the two decentralization treatments together, we obtain 35.18 per cent of subjects voting for the configuration without a global good under minimal identity and 38.42 per cent under reinforced identity $(p=0.485)$. However, these comparisons do not account for the differences in the mean contributions across treatments. We thus turn to a regression analysis.

Table 3 displays the marginal effects from the estimation of three Probit models in which the dependent variable is an indicator that the individual votes in favor of the configuration that includes no global good, with clustering of standard errors at the global group level. Each subject gives one observation. The independent variables include dummies for the decentralization and the reinforced identity manipulations, and for starting the game with three local public goods (to control for order effects). They include the subject's mean contribution to local public goods and his mean contribution 
to global public goods in the past 24 periods. We also control for individual characteristics (age, gender and relative subjective wealth). The difference between the three models is the variable used to control for the degree of cooperation in the different groups. In model (1), we add the subjects' mean earnings from the local public goods and his mean earnings from the global public goods in the previous two parts. In model (2), we include the mean contribution from the subject's two local group members to all public goods and the mean contribution of the eight global group members to the global goods in the previous two parts. Model (3) is similar to model (2), except that the mean contribution from the local group members is decomposed into local and global public goods.

Table 3: Determinants of votes for the configuration that includes no global good

\begin{tabular}{|c|c|c|c|}
\hline & (1) & (2) & (3) \\
\hline Decentralization & $-0.134 * * *(0.04)$ & $-0.135 * * *(0.04)$ & $-0.125 * * *(0.04)$ \\
\hline Reinforced local identity & $-0.025(0.05)$ & $-0.024(0.05)$ & $-0.017(0.05)$ \\
\hline Start with 3 local public goods & $0.312 * * *(0.04)$ & $0.313 * * *(0.04)$ & $0.303 * * *(0.04)$ \\
\hline $\begin{array}{l}\text { Subject's mean contribution to local public } \\
\text { goods in parts } 1 \text { and } 2\end{array}$ & $0.001(0.00)$ & $0.002(0.00)$ & $0.004 *(0.00)$ \\
\hline $\begin{array}{l}\text { Subject's mean contribution to global public } \\
\text { goods in parts } 1 \text { and } 2\end{array}$ & $0.002(0.00)$ & $0.001(0.00)$ & $0.000(0.00)$ \\
\hline $\begin{array}{l}\text { Subject's mean earnings from local goods in } \\
\text { parts } 1 \text { and } 2\end{array}$ & $0.004 *(0.00)$ & - & - \\
\hline $\begin{array}{l}\text { Subject's mean earnings from global goods in } \\
\text { parts } 1 \text { and } 2\end{array}$ & $-0.019 * * *(0.01)$ & - & - \\
\hline \multicolumn{4}{|l|}{$\begin{array}{l}\text { Mean contribution by } 2 \text { other local group } \\
\text { members in parts } 1 \text { and } 2\end{array}$} \\
\hline All public goods & - & $0.002 * *(0.00)$ & \\
\hline Local public goods & - & - & $0.001(0.00)$ \\
\hline Global public goods & - & - & $0.006^{* * *}(0.00)$ \\
\hline $\begin{array}{l}\text { Mean contribution by } 8 \text { other global group } \\
\text { members in parts } 1 \text { and } 2\end{array}$ & - & $-0.002 * * *(0.00)$ & $-0.003 * * *(0.00)$ \\
\hline$\overline{\text { Age }}$ & $-0.001(0.00)$ & $-0.001(0.00)$ & $-0.000(0.00)$ \\
\hline Female & $0.172 * * *(0.05)$ & $0.173 * * *(0.05)$ & $0.172 * * *(0.04)$ \\
\hline Relative wealth (1 to 10 ) & $0.009(0.01)$ & $0.009(0.01)$ & $0.010(0.01)$ \\
\hline Number of observations & 432 & 432 & 432 \\
\hline Pseudo-R ${ }^{2}$ & 0.180 & 0.185 & 0.195 \\
\hline$\chi^{2}$ & 114.6 & 110.2 & 121.5 \\
\hline
\end{tabular}

Notes: The table reports the average marginal effects of Probit regressions with, as dependent variable, a dummy indicating a vote in favor of the configuration that includes no global good. Standard errors, clustered at the global group level, are in parentheses. $* * *, * *$ and $*$ indicate significance at the $0.01,0.05$ and 0.1 level, respectively. 
Table 3 indicates that in the three models decentralization decreases the likelihood that a subject votes for the configuration that includes no global good by about 13 percentage points. This result is highly significant and takes the subject's and his local and global group members' cooperativeness into account. The next result rejects conjecture 3B.

Result 3.B: Controlling for contributions, reinforcing local group identity does not impact the likelihood of voting for the configuration that includes no global good.

Support for Result 3B. The percentages of individual votes for the configuration without a global good differ neither between C-I and C-MinI (proportion test, $p=0.781$ ), nor between D-I and D-MinI ( $p=0.472$ ). Moreover, Table 3 indicates that the reinforcement of local group identity has no significant effect on individual votes.

We also tested for the existence of an interaction effect between decentralization and reinforcement of local group identity to test conjecture 3C.

Result 3.C: For given contributions, reinforcing local group identity does not affect significantly the impact of decentralization on the likelihood of voting for the configuration that includes no global good.

Support for Result 3C. We estimate a slightly modified version of the first model in Table 3, by adding an interaction term between the two treatment dummies (decentralization and reinforced local identity). With this additional model, we calculate the marginal effect of decentralization on voting at the two values of the Identity treatments. We find that the marginal effect of decentralization is significant under reinforced local identity (average marginal effect $=-0.180 * * * ;$ standard error $=0.06$ ), but not under minimal local group identity (average marginal effect $=-0.092$, standard error $=0.06$ ). However, the difference between these marginal effects is not statistically significant according to a Wald test $(p=0.302)$. Thus, we reject conjecture $3 \mathrm{C}$.

Regarding the control variables, Table 3 indicates that voting for the configuration without a global good is more likely when the experiment starts with three local public 
goods. ${ }^{10}$ Subjects may believe that the higher level of cooperation experienced in the first part was supported by the structure of the public goods available itself, and not by the fact that it was the first part played. The subjects' mean contributions have no effect on voting. Considering the impact of the cooperativeness of groups' members, our final result supports conjecture 4 .

Result 4: The likelihood of a vote in favor of the configuration that includes no global good increases when local group members contribute more and it decreases when global group members contribute more.

Support for Result 4. The three models of Table 3 consider the impact of cooperation on voting under various angles and they deliver consistent results. Model (1) shows that when subjects got higher earnings from the global public goods in previous parts, they are less likely to vote for the configuration without a global good. For each additional unit of earnings, the likelihood decreases by about 2 percent points. The average earnings per period received from global public goods, over the 432 individuals, is 10.07 ECU (S.D. = 5.02 ECU). Thus, the coefficient is also economically significant: an increase of one standard deviation in mean global earnings reduces the likelihood of a vote for the break-up of the global group by 10 percent points. In contrast, the earnings from local public goods have no effect on voting. This suggests that our subjects are less likely to reject the global goods when the global group cooperates more.

Instead of earnings, models (2) and (3) consider the other group members' mean past contributions. Higher contributions from global group members reduce the likelihood of voting for the configuration that includes no global good. If they contribute one additional unit, this likelihood decreases by 0.23 or 0.32 percent, depending on the model. An increase of one standard deviation in this variable (45.43)

\footnotetext{
${ }^{10}$ Conversely, subjects who first experience a mixed configuration of public goods and then the three local goods alone are more likely to choose to keep the global group intact and, in a way, "re-unify" the global group. In other words, subjects seem to have a preference for the initial option. One possibility is that they remember those periods having larger average contributions. Since we do control for contributions, another possibility is that subjects see the first option presented as a default option.
} 
decreases the likelihood by 10.45 or 14.54 percent points. In contrast, the mean contributions of local group members increase the likelihood of voting for the configuration without a global good (model (2)). This effect is driven by the contributions to the global — and not to the local— public goods (model (3)): an increase of one unit in mean contributions from local group members to global goods increases the likelihood of a vote for the configuration that includes no global good by about 0.54 percent point. An increase of one standard deviation in this variable (16.16 units) increases this likelihood by 8.73 percent. A vote for the configuration without a global good is more likely when the local group is more cooperative at the global level. A possible interpretation is that subjects are willing to protect their cooperative local group from being exploited by possibly less cooperative other global group members. Taken together, the three models suggest that voting for the configuration without a global good is more motivated by a lower cooperation at the global level than by a higher cooperation at the local level.

\section{Discussion and conclusion}

The question that motivates this study is whether increasing the relative number of decisions made in a smaller group (our approach of decentralization) is an effective tool to quell the desires of individuals to break up with a larger group. We design a laboratory experiment that allows subjects to contribute to various numbers of local and global public goods and to vote on the presence of the global, larger, group in the last part of the experiment.

Our results show that controlling for average contributions to local and global goods, or for the average earnings of the individual from each type of good, decentralization decreases the likelihood of voting for the configuration that includes no global good. Indeed, individuals are less likely to vote such a configuration when they 
are able to make a relatively greater number of decisions within their smaller local group. Going back to our example in terms of political secessions, this result would translate in less support for secessions, or in greater support for re-unification of countries that were separated previously.

In terms of efficiency, we find that subjects earned on average significantly more in the last 12 periods when they collectively decide to have a configuration with global goods than the opposite, both under centralization (72.16 ECU per period vs. 69.55, MW $p=0.083)$ and decentralization (73.08 vs. 68.86, MW $p=0.005)$.

Moreover, increasing the number of decisions made regarding local public goods increases the contributions to these local public goods. This is in line with Bernasconi et al. (2009) who show that when faced with multiple identical public goods, subjects contribute more than when faced with a single good. However, decentralization has no effect on contributions to global public goods. As a result, decentralization does not come at the cost of efficiency.

We acknowledge that our notion of decentralization is minimal. In real settings, decentralization may be the opportunity to match different preferences with a diversity of public goods (e.g., giving different priorities to health expenditures, education programs, investments in infrastructure, etc.). Indeed, an important feature of decentralization is bringing the "government" closer to the voters, as local governments can achieve a better match between the public goods provided and the preferences of the voters. Interestingly, even with our minimal notion of decentralization, we find significant effects of increasing the relative number of decisions made at the local level on cooperation and voting. Thus, even in a very stylized and anonymous environment where all local (or global) public goods are identical, simply increasing the relative number of decisions made within a smaller group can be sufficient to increase the stability of larger groups. This is important since larger groups are theoretically able to 
reach a higher level of efficiency when people cooperate. To understand more precisely how our results apply to the concept of decentralized decision-making, a possible extension would be to introduce more differentiation between local public goods and global public goods to capture the preference matching aspect of the decentralized provision of public goods.

We find no effect of reinforced local group identity on contributions or on votes. The absence of impact of the reinforced local identity may be due to the fact that simply forming local groups is sufficient to create a strong in-group effect. On the opposite, it may be that our procedure used to reinforce identity was too weak. Using natural cultural or ethnic identities to form local groups could be an interesting extension. Moreover, local group identities were reinforced symmetrically. However, in real settings separatist movements frequently appear where one relatively small group differs from the remainder of the national community, as in Canada, Spain, or the United Kingdom. An extension could consist of strongly reinforcing local identity in one local group, but not in the others.

For the sake of simplicity, our design cannot capture every aspect of the relationship between decentralization and secessions. In particular, it is silent on its political and cultural dimensions and it does not incorporate economic inequality and conflicts over resources between local groups, which could be studied in further extensions. Nevertheless, this study is one of the first to investigate the relationship between decentralization and the stability of large groups, using experimental methods. Despite its simplicity, we believe that our design captures some important features of groups' break-ups, namely how increasing the number of decisions taken at the local level can limit the pressure of free riding at the global level. 


\section{References}

Abbink, K. and Brandts, J. (2016): Political Autonomy and Independence: Theory and experimental evidence. Journal of Theoretical Politics, 28(3): 461-496.

Akerlof, G.A., Kranton, R.E. (2000). Economics and identity. The Quarterly Journal of Economics 115(3): 715-753.

Alesina, A. and Spolaore, E. (1997). On the Number and Size of Nations. The Quarterly Journal of Economics, 112(4): 1027-1056.

Alesina, A. and Spolaore, E. (2003). The Size of Nations. MIT Press, Cambridge, MA.

Bakke, K.M., Wibbels, E. (2006). Diversity, disparity, and civil conflict in federal states. World Politics 59(1): 1-50.

Bernasconi, M., Corazzini, L., Kube, S., Maréchal, M.A. (2009). Two are better than one! Economics letters 104(1): 31-33.

Blackwell, C., McKee, M. (2003). Only for my own neighborhood? Preferences and voluntary provision of local and global public goods. Journal of Economic Behavior \& Organization 52(1): 115-131.

Blackwell, C., McKee, M. (2011). Is There a Bias Toward Contributing to Local Public Goods? Cultural Effects. Forum for Social Economics 39(3): 243-257.

Brancati, D. (2014). Another Great Illusion: The Advancement of Separatism through Economic Integration. Political Science Research and Methods 2(01): 69-95.

Buchan, N.R., Johnson, E.J., Croson, R.T.A. (2006). Let's get personal: An international examination of the influence of communication, culture and social distance on other regarding preferences. Journal of Economic Behavior \& Organization 60(3): 373-398.

Carpenter, J., Cardenas, J. C. (2011). An Intercultural Examination of Cooperation in the Commons. Journal of Conflict Resolution 55(4): 632-651.

Careaga, M., Weingast, B. (2003). Fiscal federalism, good governance, and economic growth in Mexico. In search of prosperity: analytical narratives on economic growth, 399-435.

Ceron (2015). The Politics of Fission: An Analysis of Faction Breakaways among Italian Parties (1946-2011). British Journal of Political Science 45(1): 121-139.

Chakravarty, S., Fonseca, M.A. (2014). The effect of social fragmentation on public good provision: an experimental study. Journal of Behavioral and Experimental Economics, vol. 53, December 2014, pp. 1-9.

Chaudhuri, A. (2011). Sustaining cooperation in laboratory public goods experiments: a selective survey of the literature. Experimental Economics 14 (1): 47-83.

Charness, G., Yang, C.L. (2014). Starting small toward voluntary formation of efficient large groups in public goods provision. Journal of Economic Behavior \& Organization 102: 119-132.

Chen, Y., Li, S.X. (2009). Group identity and social preferences. The American Economic Review 99(1): 431-457. 
Cinyabuguma, M., Page, T., Putterman, L. (2005). Cooperation under the threat of expulsion in a public goods experiment. Journal of Public Economics 89: 14211435.

Dal Bó, P., Foster A., Putterman L. (2010). Institutions and Behavior: Experimental Evidence on the Effects of Democracy. American Economic Review 100: 22052229.

de Souza, S.V., Dollery, B.E., Kortt, M.A. (2014). De-Amalgamation in Action: The Queensland experience. Public Management Review 17(10): 1403-1424.

de Oliveira, A.C.M., Croson, R.T.A. \& Eckel, C. (2015). One bad apple? Heterogeneity and information in public good provision. Experimental Economics 18(1): 116-135.

Ehrhart, K.M., Keser, C. (1999). Cooperation and Mobility: On the Run. SFB 504 Discussion Paper 99-69, Mannheim.

Ezgi, D. (2010). Making Secession Possible: Federalism as a Capacity Building Instrument. Annual MPSA Conference 2010, Chicago, IL. Available at: https://files.nyu.edu/de339/public/Ezgi\%20Job\%20Market\%20Paper.pdf

Falk, A., Fischbacher, U., Gächter, S. (2013). Living in Two Neighborhoods - Social Interaction Effects in the Laboratory. Economic Inquiry 51(1): 563-578.

Fellner, G., Lünser, G. K. (2014). Cooperation in local and global groups. Journal of Economic Behavior \& Organization 108: 364-373.

Festinger, L. (1954). A theory of social comparison processes. Human relations 7(2): 117-140.

Fischbacher, U. (2007). z-Tree: Zurich toolbox for ready-made economic experiments. Experimental Economics 10(2): 171-178.

Fischbacher, U., Gächter, S. (2010). Social preferences, beliefs, and the dynamics of free-riding in public good experiments. American Economic Review 100 (1): 541556.

Greiner, B. (2015). Subject pool recruitment procedures: organizing experiments with ORSEE. Journal of the Economic Science Association 1: 114-125.

Greve, H.R., Baum, C., Mitsuhashi, H., Rowley, T.J. (2010). Built to last but falling apart: Cohesion, friction, and withdrawal from interfirm alliances. The Academy of Management Journal 53(2): 302-322.

Hoffman, E., McCabe, K., Smith, V.L. (1996). Social Distance and Other-Regarding Behavior in Dictator Games. American Economic Review 86(3): 653-660.

Isaac, R.M., McCue, K.F., Plott, C.R. (1985). Public goods provision in an experimental environment. Journal of Public Economics 26(1): 51-74.

Isaac, R.M., Walker, J.M. (1988). Group Size Effects in Public Goods Provision: The Voluntary Contributions Mechanism. The Quarterly Journal of Economics 103(1): 179-199.

Isaac, R.M., Walker, J.M., Thomas, S.H. (1984). Divergent evidence on free riding: An experimental examination of possible explanations. Public Choice 43(2): 113-149.

Isaac, R.M., Walker, J.M., Williams, A.W. (1994). Group size and the voluntary provision of public goods. Journal of Public Economics 54(1): 1-36. 
Kramer, R.M., Brewer, M.B. (1984). Effects of group identity on resource use in a simulated commons dilemma. Journal of Personality and Social Psychology 46 (5): 1044-1057.

Lapointe, S. (2018). "Love thy neighbour"? The effect of income and language differences on votes for municipal secessions. Regional Science and Urban Economics 70: 229-245.

Ledyard, J. O. (995). Public goods: A survey of experimental research. In Kagel, J. and Roth, A. (eds), Handbook of Experimental Economics, 111-194.

Lustick, I.S., Miodownik, D., Eidelson, R.J. (2004). Secessionism in Multicultural States: Does Sharing Power Prevent or Encourage It? American Political Science Review, 98(2): 209-229.

Luttmer, E.F. (2001). Group loyalty and the taste for redistribution. Journal of Political Economy 109(3): 500-528.

Markussen T., Putterman L, Tyran J. (2014). Self-organization for Collective Action: An Experimental Study of Voting on Sanction Regimes. Review of Economic Studies 81(1): 301-324.

Marwell, G., Ames, R. E. (1979). Experiments on the provision of public goods. I. Resources, interest, group size, and the free-rider problem. American journal of Sociology 84(6): 1335-1360.

McCarter, M.W., Samek, A.C., Sheremeta, R.M. (2014). Divided Loyalties or Conditional Cooperation? Creating consensus about cooperation in multiple simultaneous social dilemmas. Group \& Organization Management 39(6): 744771.

Miodownik, D., Cartrite, B. (2010). Does Political Decentralization Exacerbate or Ameliorate Ethnopolitical Mobilization? A Test of Contesting Propositions. Political Research Quarterly 63(4): 731-746.

Nitta, K. (2014). The Effect of Income Heterogeneity in An Experiment with Global and Local Public Goods. University of Hawaii at Manoa Working Papers, 14(3).

Oates, W. E. (1972). Fiscal federalism. Reprint: Edward Elgar Publishing, 2011, 256 pages.

OECD (2013). Fiscal Federalism 2014. OECD Publishing.

Page, T., Putterman, L., Unel, B. (2005). Voluntary association in public goods experiments: Reciprocity, mimicry and efficiency. The Economic Journal 115(506): 1032-1053.

Pezard and Shurkin (2015). Achieving Peace in Northern Mali: Past Agreements, Local Conflicts, and the Prospects for a Durable Settlement. RAND Corporation. Santa Monica, CA. http://www.rand.org/pubs/research_reports/RR892.html.

Putterman L, Tyran J., Kamei K. (2011). Public Goods and Voting on Formal Sanction Schemes. Journal of Public Economics 95(9-10): 1213-1222.

Rand, D. G., Pfeiffer, T., Dreber, A., Sheketoff, R. W., Wernerfelt, N. C., Benkler, Y. (2009). Dynamic remodeling of in-group bias during the 2008 presidential election. Proceedings of the National Academy of Sciences in the USA 106: 6187-6191.

Rodden, J. (2002). The dilemma of fiscal federalism: Grants and fiscal performance around the world. American Journal of Political Science 46(3): 670-687. 
Sorens, J. (2004). Globalization, secessionism, and autonomy. Electoral Studies 23(4): 727-752.

Sorens, J. (2012). Secessionism: Identity, Interest, and Strategy. McGill-Queen's University Press.

Spolaore, E. (2008). Federalism, Regional Redistribution and Country Stability. In Núria Bosch, M.E. and Ollé, A.S. (Eds), The Political Economy of Inter-Regional Fiscal Flows. Edward Elgar Publishing.

Sutter M., Haigner S., Kocher M. (2010). Choosing the Stick or the Carrot? Endogenous Institutional Choice in Social Dilemma Situations. Review of Economic Studies 77: 1540-1566.

Tajfel, H., Billig, M.G., Bundy, R.P., Flament, C. (1971). Social categorization and intergroup behaviour. European Journal of Social Psychology 1(2): 149-178.

Tajfel, H., Turner, J. (1979). An Integrative Theory of Intergroup Conflict. In The Social Psychology of Intergroup Relations.

Tyran, J.-R., Feld, L.P. (2006). Achieving Compliance when Legal Sanctions are Nondeterrent. Scandinavian Journal of Economics 108 (1): 135-156.

Wachsman, Y. (2002). The effects of group interaction in a public goods experiment with two exchanges. Department of Economics, University of Hawaii at Manoa, Working Paper.

Weingast, B. R. (2006). Second generation fiscal federalism: implications for decentralized democratic governance and economic development. Stanford University. Mimeo.

Wit, A.P., Wilke, H.A.M. (1992). The effect of social categorization on cooperation in three types of social dilemmas. Journal of Economic Psychology 13 (1): 135-151.

Wong, M. (2013). Estimating Ethnic Preferences Using Ethnic Housing Quotas in Singapore. Review of Economic Studies 80 (3): 1178-1214.

Yamagishi, T., Jin, N., Kiyonari, T. (1999). Bounded generalized reciprocity: Ingroup boasting and ingroup favoritism. Advances in Group Process 16: 161-197. 


\section{Appendix 1. Figures}

Figure A1: Timeline of the C-MinI treatment

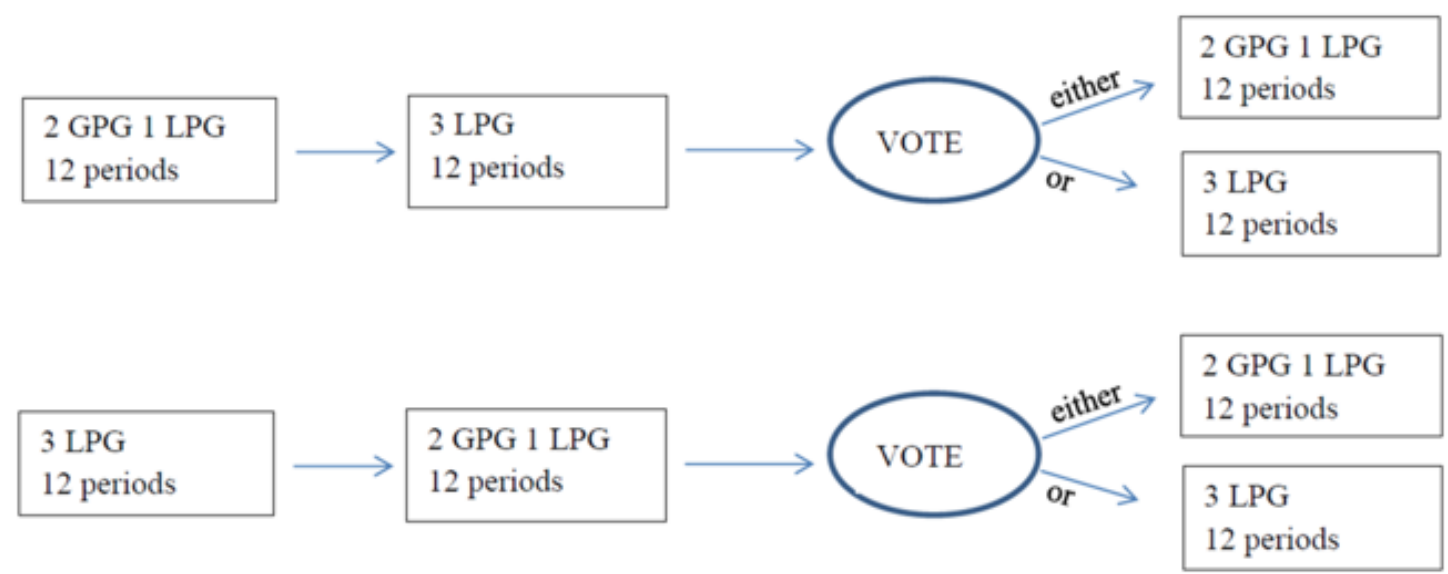

Notes: LPG for local public goods and GPG for global public goods.

Figure A2: Timeline of the D-MinI treatment

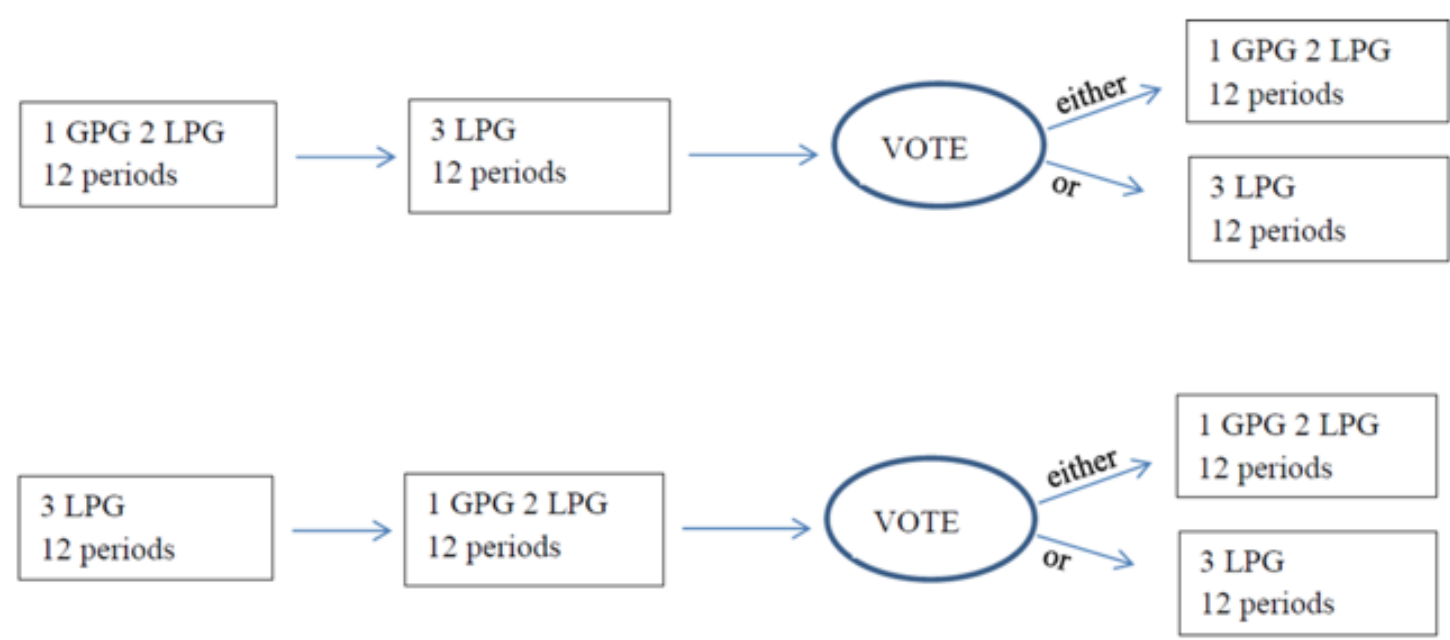

Notes: LPG for local public goods and GPG for global public goods. 
Appendix 2. Table A1: Characteristics of the experimental sessions

\begin{tabular}{|c|c|c|c|c|c|}
\hline Session & Number subjects & Treatment & Decentralization & Identity & Order: first part \\
\hline 1 & 18 & C-MinI & No & No & Mixed \\
\hline 2 & 18 & C-MinI & No & No & Mixed \\
\hline 3 & 18 & C-MinI & No & No & Mixed \\
\hline 4 & 18 & D-MinI & Yes & No & Mixed \\
\hline 5 & 18 & D-MinI & Yes & No & Mixed \\
\hline 6 & 18 & D-MinI & Yes & No & Mixed \\
\hline 7 & 9 & C-MinI & No & No & $3 \mathrm{LPG}$ \\
\hline 8 & 18 & C-MinI & No & No & $3 \mathrm{LPG}$ \\
\hline 9 & 18 & D-MinI & Yes & No & $3 \mathrm{LPG}$ \\
\hline 10 & 18 & D-MinI & Yes & No & $3 \mathrm{LPG}$ \\
\hline 11 & 9 & C-MinI & No & No & $3 \mathrm{LPG}$ \\
\hline 12 & 18 & C-MinI & No & No & $3 \mathrm{LPG}$ \\
\hline 13 & 9 & D-MinI & Yes & No & $3 \mathrm{LPG}$ \\
\hline 14 & 9 & D-MinI & Yes & No & $3 \mathrm{LPG}$ \\
\hline 15 & 9 & C-I & No & Yes & Mixed \\
\hline 16 & 9 & C-I & No & Yes & Mixed \\
\hline 17 & 9 & D-I & Yes & Yes & Mixed \\
\hline 18 & 9 & D-I & Yes & Yes & Mixed \\
\hline 19 & 9 & C-I & No & Yes & Mixed \\
\hline 20 & 9 & C-I & No & Yes & Mixed \\
\hline 21 & 9 & C-I & No & Yes & Mixed \\
\hline 22 & 9 & C-I & No & Yes & Mixed \\
\hline 23 & 9 & D-I & Yes & Yes & Mixed \\
\hline 24 & 9 & D-I & Yes & Yes & Mixed \\
\hline 25 & 9 & D-I & Yes & Yes & Mixed \\
\hline 26 & 18 & D-I & Yes & Yes & $3 \mathrm{LPG}$ \\
\hline 27 & 18 & C-I & No & Yes & $3 \mathrm{LPG}$ \\
\hline 28 & 9 & D-I & Yes & Yes & $3 \mathrm{LPG}$ \\
\hline 29 & 9 & C-I & No & Yes & $3 \mathrm{LPG}$ \\
\hline 30 & 9 & C-I & No & Yes & $3 \mathrm{LPG}$ \\
\hline 31 & 18 & C-I & No & Yes & $3 \mathrm{LPG}$ \\
\hline 32 & 18 & D-I & Yes & Yes & $3 \mathrm{LPG}$ \\
\hline 33 & 18 & D-I & Yes & Yes & $3 \mathrm{LPG}$ \\
\hline Total & 432 & & & & \\
\hline
\end{tabular}

Notes: C-MinI for centralization and minimal group identity, D-MinI for decentralization and minimal group identity, C-I for centralization and reinforced group identity, and D-I for decentralization and reinforced group identity. The Order column refers to the order of the first two parts. All subjects experienced 12 periods with a mix of local and global public goods and 12 periods with only local goods (denoted LPG). In some sessions, the first part offers a mix of local and global public goods, while in others it consists of three local goods. 


\section{Appendix 3. Instructions (translated from French)}

The following instructions are for the C-MinI treatment. We add the instructions that are specific to the D-MinI treatment and C-MinI treatment in italics into brackets. The instructions for the sessions where we control for the order effect are identical to these instructions we only invert part 1 and part 2.

\section{General information}

We thank you for participating in this experiment in economics. Your payoffs depend on your decisions. It is therefore important that you read the following instructions carefully.

Instructions are distributed for your personal use. We thank you for not communicating with other participants during the experiment.

During the experiment, we will not talk about Euros but about ECU (Experimental Currency Units). All payoffs will be calculated in ECU. At the end of the experiment, the total number of ECU that you earned will be converted into Euros at the following conversion rate:

\section{$100 \mathrm{ECU}=0.45$ Euro}

In addition to this amount, you will receive a show up fee of 5 Euros. All payments will be made in private and in cash in a separate room. Other participants will never know the amount of your payoffs in this experiment.

\section{Group formation}

Before the start of the first part, the computer program will form randomly groups composed of 9 people. Each group of 9 people is composed of three sub-groups of 3 people.

A group of 9 people is called "global group" and a sub-group of 3 people a "local group". A global group thus comprises three local groups, A, B and C.

\section{[Additional instructions for the C-I and D-I treatments:}

Each local group of 3 people within a global group is formed according to the proximity of the answers given in a questionnaire that will appear on your screen. The questionnaire consists of four proposals. For each of them, we ask you to tell if you:

- Strongly disagree

- Disagree

- Agree

- Strongly agree

Once the questionnaire is completed by each participant the computer program will use an algorithm to form the local groups according to the proximity of the answers given to these different proposals.

Thus, you will be paired in your local group with two other people in the overall group of 9 that expressed the nearest opinions to yours. You will not know at any time the detailed answers of the other participants; likewise, no one will know the details of your answers.

The two other local groups are composed of participants whose views are less similar to yours but the name of the local group (A, B, C) is independent of the distance with the opinions of your local group (for example, if you are in Group A, the members of group $\mathrm{C}$ are not necessarily further from your opinions than the members of group B). 
To sum up, each group of 9 people is composed of three sub-groups of 3 people. Groups of 9 people are randomly formed while the sub-groups of 3 are formed using the algorithm. ]

Thus, you will be at the same time a member of a local group with 2 other people and a member of a global group that includes your local group and the 6 members of the two other local groups.

The following table illustrates the composition of a global group and its local groups.

\begin{tabular}{|l|c|c|c|}
\hline Global group & Local group A & Local group B & Local group C \\
\hline participant 1 & participant 1 & & \\
participant 2 & participant 2 & & \\
participant 3 & participant 3 & participant 4 & \\
participant 4 & & participant 5 & \\
participant 5 & & participant 6 & participant 7 \\
participant 6 & & & participant 8 \\
participant 7 & & & participant 9 \\
participant 8 & & & \\
participant 9 & & & \\
\hline
\end{tabular}

For example, one participant is a member of both the global group and the local group A.

The composition of each group will remain the same throughout the experiment. You will remain paired with the same co-participants in your local group and in your global group in all parts of the experiment. You will never know the identity of your co-participants and your coparticipants will never know your identity. All decisions are anonymous. 


\section{Part 1}

The first part consists of 12 periods during which you may allocate ECU between multiple accounts. Your payoff in this section is the sum of your earnings in each period.

\section{Description of each period}

At the beginning of each period, each participant receives 60 ECU. We call this sum the "endowment". You have to decide how to allocate this endowment between your private account and several public accounts.

You have the choice to allocate the ECU in three public accounts: two global public accounts and one local public account. [This sentence is replaced by the following in the D-I and DMinI treatments: You have the choice to allocate the ECU in three public accounts: one global public account and two local public accounts.]

- The 9 members of the global group may allocate ECU to the global public account G1 and to the global public account G2. The amount of a global public account is the sum of the ECU allocated by you and the other 8 members of the global group to this account.

- Only the 3 members of your local group may allocate ECU to your local public account. The amount of your local public account is the sum of the ECU allocated by you and the two other members of your local group to this account.

Members of the two other local groups to which you do not belong also have their own local public account. The local group A can allocate ECU to the local public account A, the local group B may allocate ECU to the local public account B, and the local group C may allocate ECU to the local public account $\mathrm{C}$.

Thus, you have to decide how much of your 60 ECU you keep on your private account and how many ECU you allocate to:

- The global public account G1 (between 0 and 60 ECU)

- The global public account G2 (between 0 and 60 ECU) [In the D-I and D-MinI treatments this is replaced by: Your local public account (A, B or C) (between 0 and $60 \mathrm{ECU})$.]

- Your local public account (A, B or C) (between 0 and 60 ECU).

You must enter a value in each box on your screen. The difference between your endowment $(60 \mathrm{ECU})$ and the sum of ECU allocated to each public account remains in your private account. The sum of your ECU allocated to these accounts, public and private, cannot exceed 60 ECU.

You will make your decisions as in the screen shown in Figure 1. The consequences of your decisions are explained in details on the next page. 
Figure 1. Example of a decision screen

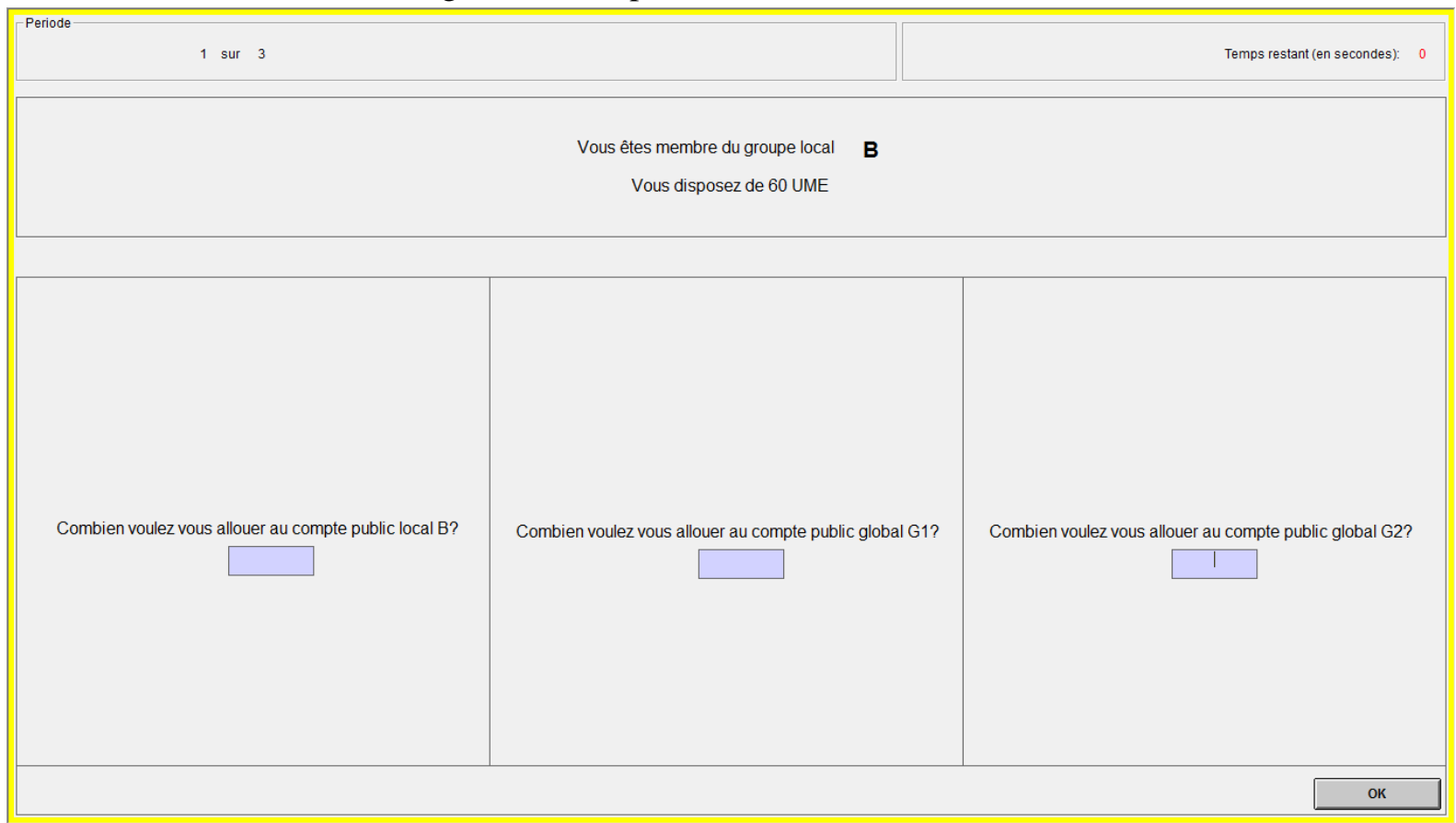

Note: accounts appeared on the computer screen in a random order.

Once all group members have decided the amount they allocate to the three public accounts, you are informed of:

- The total amount allocated to each global public account by the 9 members of the global group (including your allocation) [In the D-I and D-MinI treatments this is replaced by: The total amount allocated to the global public account by the 9 members of the global group (including your allocation).]

- The total amount allocated to each global public account by the 3 members of your local group (including your allocation) [In the D-I and D-MinI treatments this is replaced by: The total amount allocated to the global public account by the 3 members of your local group.]

- The total amount allocated to your local public account by the 3 members of your local group (including your allocation). [In the D-I and D-MinI treatments this is replaced by: The total amount allocated to your local public accounts by the 3 members of your local group (including your allocation).]

Your screen will also remind you the amount of your allocation to the global public accounts and the local public account and the amount held on your private account. [This sentence is replaced by the following in the D-I and D-MinI treatments: Your screen will also remind you the amount of your allocation to the global public account and to the local public accounts and the amount held on your private account.] It also shows your payoff in that period. You are not informed of the amounts allocated to local public accounts by the two other local groups.

Figure 2 reproduces the feedback screen at the end of a period. 
Figure 2. Example of the feedback screen displayed at the end of a period.

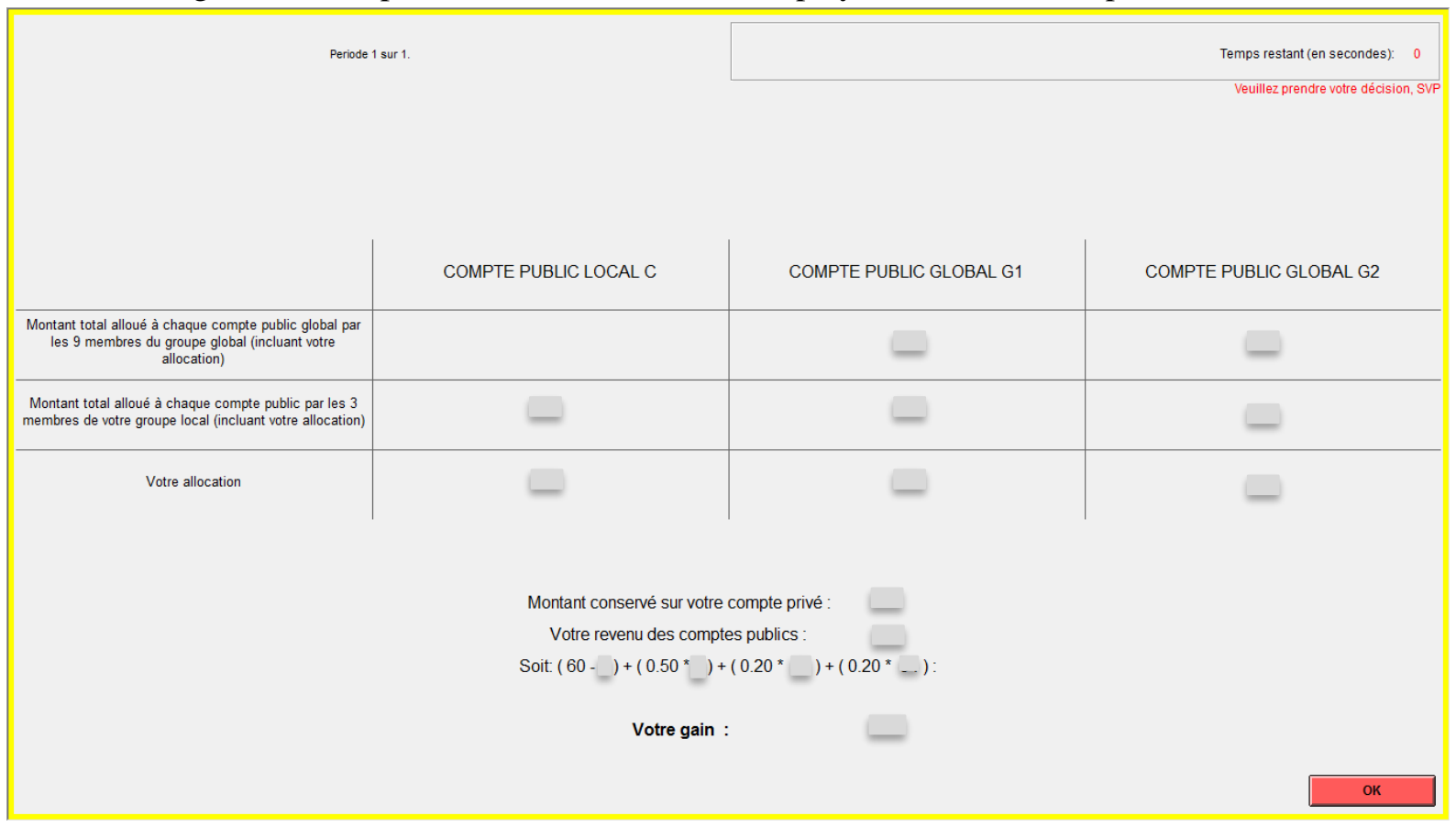

\section{Calculation of your payoff}

The payoff from a public account is different depending on whether it is a global public account or a local public account:

- The payoff from each global public account represents $20 \%$ of the sum of the 9 individual allocations to this global public account, [This sentence is replaced by the following in the D-I and D-MinI treatments: The payoff from the global public account represents $20 \%$ of the sum of the 9 individual allocations to the global public account, ]

- The payoff from the local public account represents $50 \%$ of the sum of the three individual allocations to the local public account. [This sentence is replaced by the following in the D-I and D-MinI treatments: The payoff from each local public account represents $50 \%$ of the sum of the three individual allocations to this local public account.]

Your payoff at each period is calculated using the following formula (if you have difficulty understanding these formulas do not hesitate to ask questions):

$\begin{aligned} & \text { Payoff in a period }=\text { Your endowment in ECU } \\ &- \text { Your allocation to the two global public accounts and the local public account } \\ &+20 \% \text { of the total number of ECU allocated to the global public account G1 } \\ &+20 \% \text { of the total number of ECU allocated to the global public account G2 [In the D-I and } \\ & \text { D-MinI treatments this sentence is replaced by: } \\ &+50 \% \text { of the total number of ECU allocated to your local public account (A, B or C)] } \\ &\end{aligned}$

This formula shows that your payoff at the end of a period consists of two parts:

1) the ECU that you have kept for yourself (namely your endowment - your allocation to the public accounts) 
2) the sum of the total payoffs from both global public accounts and your local public account. [This sentence is replaced by the following in the D-I and D-MinI treatments: of the sum of the total payoff from the global public account and your two local public accounts.]

Here are some examples.

\section{Example 1}

Suppose that the sum of the allocations of the 3 members of a local group to their local public account is 90 ECU. Suppose also that the sum of the allocations of the 9 members of the global group is $70 \mathrm{ECU}$ to the global public account 1 and $300 \mathrm{ECU}$ to the global public account 2. In this case, the payoff from the public accounts is:

$50 \%(90)+20 \%(70)+20 \%(300)=45+14+60=119 E C U$

[This example is replaced by the following in the D-I and D-MinI treatments: Suppose that the sum of the allocations of the 3 members of a local group is 90 ECU to their local public account 1 and 70 ECU to their local public account 2. Suppose also that the sum of the allocations of the 9 members of the global group is 300 ECU to the global public account. In this case, the payoff from the public accounts is:

$50 \%(90)+50 \%(70)+20 \%(300)=45+35+60=140 E C U]$

\section{Example 2}

Suppose that the sum of the allocations of the 3 members of a local group to their local public account is 60 ECU. Suppose also that the sum of the allocations of the 9 members of the global group is $90 \mathrm{ECU}$ to the global public account 1 and $50 \mathrm{ECU}$ to the global public account 2. In this case, the payoff from the public accounts is:

$50 \%(60)+20 \%(90)+20 \%(50)=30+18+10=58 E C U$.

[This example is replaced by the following in the D-I and D-MinI treatments: Suppose that the sum of the allocations of the 3 members of a local group is $60 \mathrm{ECU}$ to their local public account 1 and 90 ECU to their local public account 2. Suppose also that the sum of the allocations of the 9 members of the global group is $50 \mathrm{ECU}$ to the global public account. In this case, the payoff from the public accounts is:

$50 \%(60)+50 \%(90)+20 \%(50)=30+45+10=85 E C U$.

You always have the option to keep the ECU on your private account or to allocate them to a public account. Each ECU you keep on your private account increases your payoff in the current period by 1 ECU.

If you allocate $1 \mathrm{ECU}$ to a public account, the total allocation to this public account increases by $1 \mathrm{ECU}$. In this case, your payoff increases by $50 \% \times 1=0.5 \mathrm{ECU}$ if it is a local public account and by $20 \% \times 1=0.2 \mathrm{ECU}$ if it is a global public account. Your allocation to a public account also increases the payoff of other members:

- If it is a local public account, the payoff of the two other members of your local group will also increase by $0.5 \mathrm{ECU}$ each. So, the total payoff of your local group from your local public account will be increased by $3 \times 0.5=1.5 \mathrm{ECU}$.

- If it is a global public account, the payoff of the eight other members of the global group will also be increase by $0.2 \mathrm{ECU}$ each. So, the total payoff of the global group from the global public account is increased by $9 \times 0.2=1.8 \mathrm{ECU}$.

Similarly, your payoff increases for each ECU allocated to a global public account by the other members of the group and for each ECU allocated to your local public account by the other 
members of your local group. For each ECU allocated by another member of your local group or global group, you earn 0.5 and $0.2 \mathrm{ECU}$ respectively.

However, your payoff is not affected by the ECU allocated by members of other local groups to their local public account.

\section{To sum up:}

- You receive an endowment.

- You decide on your allocation to two global public accounts and one local public account.

[This sentence is replaced by the following in the D-I and D-MinI treatments: You decide of your allocation to one global public account and two local public accounts.]

- You are informed on the amount of allocation to each global public account and local public account associated with your local group and your payoff. [This sentence is replaced by the following in the D-I and D-MinI treatments: You are informed on the amount allocated to the global public account and to each local public account by your local group members, and on your payoff.]

At the end of each period, a new period starts automatically. You receive a new endowment 60 ECU.

$$
* * *
$$

Please read again these instructions. If you have any question, raise your hand and we will answer to your questions in private. Thank you to fill out the understanding questionnaire that has been distributed. We will come to you to check your answers in private.

\section{Part 2}

\section{(distributed after completion of Part 1 and the questionnaire)}

The second part consists of 12 periods. Your payoff in this section is the sum of your earnings in each period. The composition of your local group and your global group is the same as in the previous part, but in this part you will only interact with the other two members of your local group.

\section{Description of each period}

The second part is similar to the first part: at the beginning of each period, each participant receives $60 \mathrm{ECU}$ and has to decide how to allocate this endowment between his private account and three public accounts.

The only difference with the previous part is that the three public accounts are now three local public accounts.

Only three members of your local group may allocate ECU to your local public accounts. The amount of the local public accounts is the sum of the ECU allocated by you and the two other members of your local group to these accounts.

Members of the two other local groups to which you do not belong also have their own local public accounts. The local group A may allocate ECU to the local public accounts A1, A2 and A3; the local group B may allocate ECU to the local public accounts B1, B2 and B3; and the local group $\mathrm{C}$ may allocate $\mathrm{ECU}$ to the local public accounts $\mathrm{C} 1, \mathrm{C} 2$ and $\mathrm{C} 3$. 
Thus, you need to decide how much of your 60 ECU you keep on your private account and how much you allocate to:

- Your local public account 1 (A, B or C) (between 0 and $60 \mathrm{ECU}$ )

- Your local public account 2 (A, B or C) (between 0 and 60 ECU)

- Your local public account 3 (A, B or C) (between 0 and 60 ECU)

You must enter a value in each box displayed on your screen. The difference between your endowment (60 ECU) and the sum of the ECU allocated to each public account remains on your private account. The sum of all your ECU allocated to these accounts, public and private, cannot exceed 60 ECU.

Once all group members have decided the amount they allocate to these three public accounts, you are informed on the total amount allocated to each of the three local public accounts by the 3 members of your local group (including your allocation).

Your screen will also remind you the amount of your allocation to each local public account and the amount held on your private account. It also shows your payoff in that period. You are not informed of the amounts allocated to local public accounts by the two other local groups.

\section{Calculation of your payoff}

The payoff drawn from each local public account represents 50\% of the sum of the 3 individual allocations to this local public account.

Your payoff at each period is calculated using the following formula:

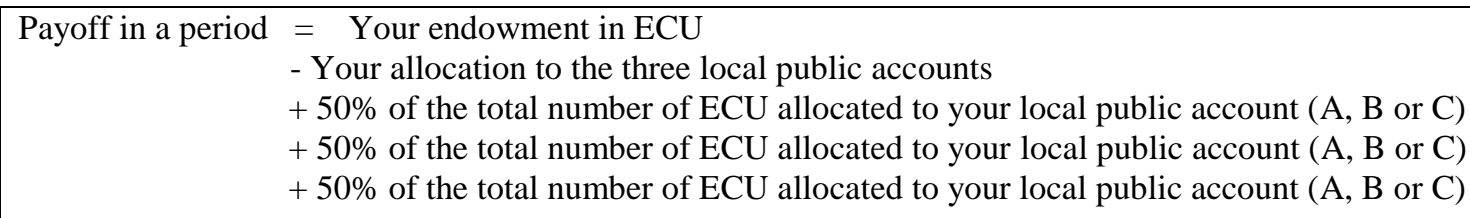

This formula shows that your payoff at the end of a period consists of two parts:

1) the ECU that you have kept for yourself (namely your endowment - your allocation to the public accounts)

2) the sum of the total payoffs from your local public accounts.

As previously, each ECU you keep in your private account increases your payoff in the current period by 1 ECU. If you allocate 1 ECU to a local public account, the total allocation of this public account increases by $1 \mathrm{ECU}$. In this case, your payoff increases by $50 \% \times 1=0.5 \mathrm{ECU}$. The payoff of two other members of your local group will also be increased by 0.5 ECU each. Thus, the total payoff of the local group from the local public account will be increased by $3 \times$ $0.5=1.5 \mathrm{ECU}$.

Similarly, your payoff increases by $0.5 \mathrm{ECU}$ for each ECU allocated to a local public account by the other members of your local group. However, your income is not affected by the ECU allocated by the members of other local groups to their local public accounts. 
At the end of each period, a new period starts automatically. You will receive a new endowment of $60 \mathrm{ECU}$.

Please read again these instructions. If you have any question, raise your hand and we will answer to your questions in private.

\section{Part 3}

(distributed after completion of Part 2)

The third part consists of 12 periods. Your payoff in this section is the sum of your payoffs in each period. The composition of your local group and your global group is the same as in the previous parts.

\section{Choice of the available public accounts}

Before the start of the first period, you have to vote to select the nature of the public accounts that will be available for the next 12 periods. You will vote only once in this part.

You can choose between two options:

- An option with one local public account and two global public accounts (as in part 1)

[This sentence is replaced by the following in the D-I and D-MinI treatments: An option with two local public accounts and one global public account (as in part 1).]

- An option with three local public accounts (as in Part 2).

If the option with one local public account and two global public accounts is selected [This sentence is replaced by the following in the D-I and D-MinI treatments: If the option with two local public accounts and one global public account is selected], you will interact at the same time with the 2 other members of your local group and with the members of the other two local groups (i.e., with 8 other people).

If the option with three local public accounts is selected, you will only interact with the two other members of your local group.

Once all the members have voted, the computer program calculates the majority choice in each of the three local groups. The option that will be applied to the next 12 periods of the game is the one that was chosen by the majority of the three local groups within your global group of 9 people.

Before the start of the first period, you are informed on the outcome of the vote in your local group and on the majority choice in the global group. You are not informed about the details of the votes in your local group nor in other groups.

\section{Description of each period}

You receive an initial endowment of $60 \mathrm{ECU}$ at the beginning of the period. Depending on the majority vote, you can allocate the ECU of your endowment either between your private account, a local public account and two global public accounts (according to the rules of Part 1) [This sentence is replaced by the following in the D-I and D-MinI treatments: you can allocate the ECU of your endowment either between your private account, two local public accounts and one global public account (according to the rules of Part 1)] or between your private account and three local public accounts (according to the rules of Part 2).

$$
* * *
$$

Please read again these instructions. If you have any question, raise your hand and we will answer to your questions in private. 


\section{Appendix 4. Questionnaire used for the formation of groups}

Please read each statement very carefully and evaluate how much you agree or disagree with each one of them. For each statement, give your answer by checking the box that best describes your opinion.

You can only choose one answer from the following options:

1. Strongly disagree

2. Disagree

3. Agree

4. Strongly agree

Statement 1: I enjoy visiting museums of contemporary art.

Statement 2: Surrogate motherhood should be authorized.

Statement 3: I am willing to consume genetically modified food.

Statement 4: I love practicing sports. 